\title{
Voter conformism and inefficient policies
}

\author{
Cécile Aubert ${ }^{1,2} \cdot$ Huihui Ding ${ }^{3}$
}

Received: 21 October 2019 / Accepted: 25 January 2022 / Published online: 19 February 2022

(c) The Author(s), under exclusive licence to Springer-Verlag GmbH Germany, part of Springer Nature 2022

\begin{abstract}
A reelection-seeking politician makes a policy decision that can reveal her private information. This information bears on whether her political orientation and capabilities will be a good fit to future circumstances. We study how she may choose inappropriate policies to hide her information, even in the absence of specific conflicts of interests, and how voters' conformism affects her incentives to do so. Conformism is independent from policies and from voters' perceptions. Yet we identify a 'conformism advantage' for the incumbent that exists only when there is also an incumbency advantage. Conformism changes the incentives of the incumbent and favors the emergence of an efficient, separating equilibrium. It may even eliminate the pooling equilibrium (that can consist in inefficient persistence). Conformism has a mixed impact on social welfare however: it improves policy choices and the information available to independent voters, but fosters inefficient reelection in the face of a stronger opponent. When the incumbent is 'altruistic' and values social welfare even when not in power, she partly internalizes this latter effect. The impact of conformism is then non monotonous.
\end{abstract}

\section{Introduction}

Conformism - a desire to behave as others, in a reference group, do-is a source of concern in democracies as it can give rise to different kinds of herd behaviors in voting. Some individuals will tend to vote for the same party, or favor the same policies, as their parents or neighbors. This is a reason for strong partisanship and it

Cécile Aubert

cecile.aubert@tse-fr.eu

Huihui Ding

huihui.ding@u-cergy.fr

1 Bordeaux School of Economics, Univ. Bordeaux, CNRS, BSE, UMR 6060, Pessac, France 33600

2 Toulouse School of Economics, Université Toulouse Capitole, 31000 Toulouse, France

3 THEMA, CNRS UMR 8184, Université de Cergy-Pontoise, 33, Boulevard du Port, 9501 Cergy-Pontoise Cedex, France 
makes voters less responsive to the efficiency of policies (Bartels 2002; Gerber and Huber 2009). ${ }^{1}$ Another form of conformism is that some voters want to be on the winning side. This is a reason for the 'bandwagon effect': voters are more likely to vote for a candidate if they expect this candidate to win (Lee 2011; Panova 2015). ${ }^{2}$ This is why many countries ban opinion surveys in the last days before an election. Herd behavior is a problem for democracies, as it can give rise to crowd manipulation. ${ }^{3}$ Both partisanship and the desire to be on the winning side affect the reelection chances of an elected politician. As a consequence, conformism in its different guises can affect the decisions a politician takes during her mandate.

Allowing elected politicians to run for a second mandate is an incentive mechanism: It should push them to serve voters' needs in order to be reelected-in contrast to public servants and judges whose term is independent from their decisions (Maskin and Tirole 2004). One drawback is that politicians may pander to cater to some voters' needs or tastes, by selecting policies that a large part of the electorate likes. A broader definition of 'pandering' includes any inefficient behavior taken by incumbents in order to get reelected, from inadequate policy choices to inefficient policy persistence (Majumdar and Mukand 2004; Panova 2015). Conformism can induce pandering because conformist voters may (inaccurately) believe some policy to be superior, leading politicians to enact this policy to improve their reelection odds (Ashworth et al. 2010a). We study a different context, whereby conformism consists in a desire to be on the wining side. This conformism is not directly associated to any policy preference. Yet, together with partisanship by some voters, it can indirectly determine whether an incumbent will take inefficient decisions. The impact of conformism on social welfare is not trivial, and can be positive.

The link between conformism and policy efficiency that we study is indirect. It can exist even if voters' beliefs are accurate and unaffected by conformism. It arises because of the signaling properties of policy choices. Some policies are a better match than others to fine circumstances that are unknown (at the time of the election) to voters. These circumstances correlate with the type of competencies, political program and values, that will best match future circumstances. The incumbent's characteristics may be more or less fitted to these circumstances. For instance, a left-wing incumbent may obtain better results than her right-wing opponent in a crisis context where social measures are needed; The reverse may hold in a context of economic expansion where laisser-faire can favor firms innovation. As in Falk and Zimmermann (2017) or Tajika (2021), policy consistency can also signal higher ability: The incumbent may thus inefficiently persist (Ashworth et al. $2010 b$ ) in failing policies. Some moves on the international scene can be more likely to succeed, in a complex geopolitical context, if the incumbent has political support

\footnotetext{
1 People who identify with the governing party perceive the results of economic policy more positively than subjects who identify with the opposition.

2 Many authors have confirmed the bandwagon effect, both empirically (Hodgson and Maloney 2013; Kiss and Simonovits 2014) and experimentally (Bischoff and Egbert 2013; Morton et al. 2015; Agranov et al. 2017).

${ }^{3}$ Callander (2007) develops a model of sequential voting to argue that voters' desire to win (by voting like most others do, and thus belonging to the majority) is critical to the existence of the bandwagon.
} 
from a particular subset of foreign governments. The optimal moves depend on a complex match between the incumbent's personal and political characteristics, and the current diplomatic context, which is not well known to voters. Which diplomatic move is optimal can correlate with the chances of reaching beneficial agreements in a future mandate. In that case, a weak negotiator may inefficiently engage in strong moves in order to hide her worse perspectives to domestic voters. "Pandering" in our model consists in choosing a policy that is not appropriate to the context, in order to hide information on the state of the world. Voters conformism is totally independent from the policies' intrinsic quality; Yet the desire from voters to be on the winning side, associated with unbalanced partisanship, modifies the electoral benefits of choosing inefficient policies.

Despite the widespread concerns that conformity allows for manipulation, the desire to vote for the winner can have a beneficial impact on social welfare. This is because it can foster the choice of efficient policies, despite their signaling features. This beneficial impact arises only if there exists an incumbency advantage. Such an advantage exists when the incumbent benefits from more votes, ceteris paribus, than her opponent would have had with the same platform. Incumbency advantage is well documented ${ }^{4}$ and appears to be a critical determinant of success in reelections. ${ }^{5}$ Conformism amplifies the incumbency advantage, thereby lessening the impact of signaling. It determines which equilibria can arise.

Our framework The incumbent ${ }^{6}$ cares not only about choosing the right policies but also about the 'rents' derived from being in power. She has private and full information on the decision that maximizes welfare. The appropriate decision is correlated with her ability to generate welfare in the future. For this reason, she may want to distort her choice before running for a second mandate (we provide an illustration based on the 2020 US Presidential elections below).

There are three types of voters: the incumbent's partisans, the opponent's partisans, and the independent voters, who are conformists (Bartels 2000). Although using a single representative independent voter is a standard assumption in the theoretical literature (Canes-Wrone et al. 2001), partisans form a large share of voters (Swank 1995; Feddersen and Pesendorfer 1996, 1997; Bartels 2000, 2002; Brader and Tucker 2009; Klar 2014; Helland and Sørensen 2015). While partisans are passive players by definition, separating voters into these categories allows us to model

\footnotetext{
4 See Erikson (1971), Gelman and King (1990), Ansolabehere (2002), Ashworth and Mesquita (2008), Lee (2008), Hodler et al. (2010), Erikson and Titiunik (2015) and Fiva and Røhr (2018). The many causes of incumbency advantage include bureaucratic relations, pork barrel spending, campaign finances and practices (Ansolabehere et al. 2006), and the structure of intra-party competition (Ansolabehere et al. 2007). Holding office helps incumbents obtain more media coverage (Prior 2006) and additional financial support for their campaigns (Gerber 1998).

5 See Levitt and Wolfram (1997), Trounstine (2011) and Snyder et al. (2015). Levitt and Wolfram (1997) report that incumbents can achieve reelection rates of around 90\%. Lee (2008) shows that in Congressional elections, a party which wins with a small number of additional votes in a very close election (suggesting that the electorate is very balanced between the party and its opponent) has a $35 \%$ higher probability of winning the next election.

6 For convenience, we refer to a politician as 'she' and to a voter as 'he'.
} 
the advantage that arises from the existence of a larger proportion of partisans for the incumbent. We refer to this advantage as the 'incumbency advantage' and it turns out to be essential in explaining the impact of conformism in our setup.

When the incumbent benefits from an incumbency advantage, voting for the opponent comes with a higher risk of not being on the winning side. This is costly to conformist voters. This effect plays in favor of the incumbent as if the opponent's capabilities were lower than they really are. This 'conformism advantage' is at the core of the results we obtain.

We show that conformism affects social welfare through several channels, even though this conformism is fully independent from policies. Conformism advantage reduces reelection pressure, and lessens the cost of choosing a policy that reveals 'bad news' about oneself. We study the conditions under which two polar pure strategy Perfect Bayesian Equilibria (PBE) exist: In the socially efficient equilibrium (shortened to $\mathbf{S}$ ), the incumbent selects the policy that best promotes the social interest; In the pooling, pandering equilibrium (shortened to $\mathbf{P}$ ), the incumbent selects a policy that will be interpreted by voters as 'good news' on her capabilities, irrespective of her private information on its appropriateness.

Voters' desire to be on the winning side turns out to make pandering less likely. Its total impact on social welfare depends on the exact configuration considered: More conformism improves the efficiency of policy choices (which also improves voters' information at the time of the election). But it has the drawback of leading to re-electing the incumbent too often.

The fact that the incumbent cares for social welfare even when not in power (she is 'altruistic'), is not necessarily welfare-improving. She then internalizes her impact on candidate selection (that is: the impact of her choices on the probability of being re-elected when the opponent would be better able to raise welfare). More conformism increases the risk of inadequate candidate selection but improves the incentives to select efficient policies. The two effects can run contrary to one another, making the conditions for a separating equilibrium more difficult to meet.

An illustration-The 2020 US elections The campaign of incumbent Donald Trump for the 2020 US presidential election might be interpreted in the light of the mechanism we model. Trump systematically minimized the importance of the COVID-19 epidemic, despite evidence from scientists and hospitals. He asserted the primacy of individual freedom over distancing measures-which can be seen as traditional pandering to an electorate that values freedom of movement. But he also persisted in other decisions that denied the severity of the crisis (e.g., maintaining campaign meetings despite contagion risks and a fast rise in number of cases, not wearing a mask in public until July 2020...) Such decisions were ways of denying his own incorrect initial assessment of the crisis. This mistake could indeed cast doubts on his abilities. This could be an example of inefficient persistence for signaling reasons (a special case of our model).

In addition, the severity of the crisis also correlated to the type of qualities and of policies that were going to be most appropriate in the near future. A more severe crisis required a leader willing to follow medical experts and to intervene more in the individual and economic arenas. Both requirements favored Trump's opponent, 
Bidden. ${ }^{7}$ Beliefs about the severity of the Covid epidemic, and its time horizon, diverge according to political orientation (Pew Research Center 2020). And the divergence became more polarized during the campaign, as it was emphasized by candidates (despite converging medical information). ${ }^{8}$ Trump continuously insisted on his high chances of winning thanks to his strong partisan support. ${ }^{9}$ This communication emphasizing his incumbency advantage could have had as an objective to trigger a conformist reaction from undecided voters. Although this strategy was not sufficient to obtain re-election, it fits well the situation and strategies we model.

\subsection{Related literature}

Conformism. Conformism is when an individual in a group displays a certain behavior because it is what the individual has witnessed most frequently in others (Claidière and Whiten 2012), as shown in the pioneering experiments in Asch (1951). The desire to conform makes people want to belong to the majority. Conformity motivations can be informational, i.e., arise from desire to form an accurate interpretation of reality and behave correctly. Or they can be normative, i.e., based on the goal of obtaining social approval from others (Deutsch and Gerard 1955; Cialdini and Goldstein 2004). ${ }^{10}$

Inefficient signaling via policies. Panova (2015) studies how policy persistence and the bandwagon effect can arise from signaling effects. In her model some voters are informed and others are not. Due to their awareness of their limited memory, voters interpret signals about policies as complementing their limited recall, which lends these policies more weight. While in Panova (2015), the conformism arises from limited information and causes policy persistence, in our (very different) setup the reverse effect can arise: When voters' desire to win is strong, voting

\footnotetext{
7 "COVID-19 has changed the tenor of the election in unmistakable ways. [...] The pandemic has brought new urgency to issues like access to health care, inequality and the social safety net, while driving Trump's preferred topics of immigration and trade out of the picture" [...] "Biden's strengths suddenly seem matched to the moment". (Time magazine, August 17, 2020).

${ }^{8}$ Surveys indicate that Republicans have consistently been less likely than Democrats to say that they fear being hospitalized because of COVID-19 or that they might unknowingly spread the virus to others (Pew Research Center 2020). This partisan gap has widened significantly between April and June 2020. Importantly, Republicans are also more likely to say they think the worst is behind us. Here also, the difference with Democrats has widened.

9 "Trump's campaign insists he is positioned for victory despite the headwinds. Public polls are undercounting Republicans, says Miller, the Trump political adviser, and the President's supporters are more enthusiastic about voting by a 2-to-1 ratio" (Time magazine, August 17, 2020).

${ }^{10}$ In economics, Zafar (2011) experimentally highlights that informative conformity matters for decision-making, in the shape of learning about the descriptive norm (i.e., what others are doing). Grodner and Kniesner (2006) study the effect of normative conformity on wages and labor supply. Ding (2017) models normative conformity as the desire to vote like the majority when voting on collective decisionmaking under the unanimity rule. Pivato (2017) develops a theory of epistemic democracy with correlated voters where the voters influence one another via a social network, because of normative conformity.
} 
for the incumbent becomes more attractive, and this can eliminate inefficient persistence of failing policies. Our modeling of policies incorporates as a special case a setting similar to Dur (2001), in which repealing an implemented policy is a bad signal to uninformed voters about an incumbent's policy competence. The incumbent may choose to always to continue her policy, even if it is a failure. Majumdar and Mukand (2004) study the related issue of policy experimentation by an incumbent. The latter may inefficiently select which policies to experiment, and may inefficiently persist; Policy persistence can arise to signal confidence in future adequacy despite publicly observable failure (because failure at the time of the election can be due to random circumstances). Contrary to our set-up, voters in Dur (2001) and Majumdar and Mukand (2004) have common interests and are treated as a single representative independent voter.

The remainder of the paper is organized as follows. Section 2 describes the model. Section 3 defines the equilibria and the impact of conformism on an independent voter's choice. Section 4 analyzes how conformism affects the equilibria. Section 5 studies the overall impact of conformism on social welfare and Sect. 6 provides results for the special case of a partly altruistic incumbent.

\section{The model}

We model an election in which voters can reelect an incumbent, after observing her decision to continue or repeal her past choices, or instead vote for the opponent.

\subsection{Context, decisions and expected welfare}

There is no conflict of interest in policy choices between voters, or between voters and politicians. However the incumbent is better informed on which decision should be made before the end of her mandate, and the appropriate decision is correlated with her own ability to create welfare in the future.

\section{- Context and first-period decisions}

The incumbent privately observes a fully informative signal $s, s \in\{a, b\}$, about the state of the world, the 'context' (signal and state are identical). ${ }^{11}$ This signal perfectly correlates with the decision $d$ the incumbent should take before the end of her first mandate: Decision $d=A$ is socially efficient if $s=a$ and $d=B$ is socially efficient if $s=b$.

The ex ante probability that the signal is equal to $a$ is $\mu, \mu \in] 0,1[$.

The first-period social benefits $b_{1}$ ensuing from decision $s$ are as follows:

- Selecting $d=A$ when $s=a$ generates a first-period benefit normalized to 1 .

- Selecting $d=B$ when $s=b$ generates a first-period benefit normalized to 0 .

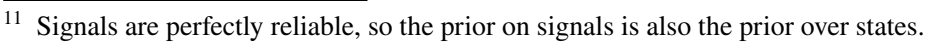


- Selecting a non-congruent decision (either $d=A$ when $s=b$, or $d=B$ when $s=a)$ generates a first-period loss $-L<0$.

Signal $b$ is 'bad news' about the first period since it corresponds to a lower benefit. The normalization to 1 and 0 has no qualitative impact; it allows to easily interpret our set-up in the special case of policy persistence: Then $a$ means that current policies are 'appropriate' (and should be continued), while $b$ means they are a failure; $A$ consists in persisting in a policy, while $B$ means repealing it. Repealing the policy nullifies the costs it would have had when it is inappropriate $(s=b)$. In the context of the COVID-19 crisis presented in the introduction, labels $A$ and $B$ can depend on the political orientation of the incumbent. Consider an incumbent whose platform makes it easier to support economic laisser-faire and individual freedom; $A$ would mean giving priority to individuals' autonomy, while $B$ would be taking strong measures to stop the epidemic; $A$ is best if the epidemic is weak $(a)$, while $B$ is best if it is severe $(b){ }^{12}$

\section{- Context and second-period prospects.}

The signal $s$ also correlates with the appropriateness of the incumbent's characteristics (political orientation, personal abilities, network, etc) with future circumstances: Signal $b$ is also 'bad news' about the incumbent's ability to generate social benefits in the future if she is reelected. ${ }^{13}$ The expected benefit the incumbent will generate in the second-period if reelected is $\mu^{a}$ if $s=a$ and $\mu^{b}$ otherwise, with $1>\mu^{a}>\mu^{b}>0$.

The expected benefit generated by an opponent is $\mu^{o}$. It is unknown to the incumbent at the time she takes decision $d$. It follows a uniform distribution on $[0,1]$. We denote $G($.$) and g($.) the c.d.f. and density functions (these notations are not necessary but help understand some mathematical expressions). The exact value taken by $\mu^{o}$ becomes known to voters before the election. ${ }^{14}$

- Beliefs.

Both candidates do not know their own ability to generate benefits in the future. However the incumbent has superior information on her ability (compared with her opponent) since she observes the signal $s$. Other players can only observe the decision $d$ she subsequently takes.

As a consequence, the incumbent updates her beliefs about her 'appropriateness' to $\mu^{s}$, for $s=a, b$, which equals the expected benefit conditional on signal $s$.

We denote $\mu^{E}(d)$ the voters' updated belief, which derives from Bayes' rule in equilibrium $E$ given decision $d$. We will consider three different types of equilib-

\footnotetext{
12 If the incumbent was instead from a party more favorable to interventionism, the labels $a, b, A$ and $B$ would have to be inverted.

13 The expected benefit can be interpreted as the probability that the incumbent will make decisions leading to a benefit of 1 , rather than 0 , if she is reelected.

14 Because the voters' perceptions of the incumbent's quality can be shaped by many observations pertaining to her first mandate, which is not the case for the challenger, perceptions about their ability need not follow the same distribution.
} 
ria, separating $(E=\mathbf{S})$, pooling $(E=\mathbf{P})$ and mixed $(E=\mathbf{M})$. In a Perfect Bayesian Equilibrium (PBE), updated beliefs are coherent given the players' strategy, and they therefore depend on the type of equilibrium considered. ${ }^{15}$

\subsection{The voters}

A proportion of voters are partisans who always vote for their preferred candidate, independently of the incumbent's policy performance and other voters' actions. The other voters are independent and conformists, who have a desire to 'win' and belong to the majority, in addition to wishing to select the most able candidate. We assume that they are represented by a single representative independent voter. This avoids issues related to coordination and to the probability of each single independent voter being pivotal. ${ }^{16}$

The utility of the independent voter is the expected welfare generated by the second-period policy, plus a 'conformity bonus' $W$ obtained if and only if he has voted for the winner.

\subsection{Incumbency advantage and reelection odds}

Assumption 1 (Incumbency advantage) If the incumbent is selected by the independent voter, she wins with certainty. Otherwise, she wins with probability $p$, $p \in(0,1)$.

The incumbent's partisans form a majority with probability $p$. The independent voter is pivotal with probability $1-p$ (and he does not know the size of the incumbent's partisan support at the time of voting). Probability $p$ inversely measures the importance of independent voters, and the extent to which policy choices can change the outcome of the election. A lower value of $p$ means greater reelection pressure. ${ }^{17}$

We denote $v(d)$ the independent voter's strategy (probability of voting for the incumbent) when he observes decision $d$ and has beliefs $\mu^{o}$ on the opponent. From the point of view of the incumbent, who cannot observe $\mu^{o}$ at the time of choosing $d$, her (re-)election probability is $e(d)=\mathbf{E}[v(d)+(1-v(d)) p]=p+(1-p) \mathbf{E} v(d)$.

\footnotetext{
${ }^{15}$ We use the same letter, $\mu$, for all beliefs about politicians' ability. However it should be clear that the revised beliefs of players depend on their information: the signal $s$ for the incumbent, the decision $d$ taken by the incumbent for the voters. Beliefs about the opponent, $\mu^{o}$, are exogenous from the point of view of the players.

${ }^{16}$ The desire to pick the winner should not systematically override the desire to achieve good policies. To avoid dealing with multiple conditions (to ensure that this is true for all configurations), we adopt a representative voter. The literature on voter turnout has often used the concept of the quasi-symmetric mixed-strategy Nash equilibrium in which voters in favor of the same alternative use the same strategy. In our specific context, this boils down to a representative voter. Media coverage, opinion polls and political advertising can serve as coordination devices.

17 To simplify mathematical expressions, we assume that the opponent can never win without the independent vote. The analysis could be extended to the more general case in which her probability of wining without support from the independent voter is lower than the corresponding probability $(p)$ for the incumbent.
} 


\subsection{The incumbent's objective}

The expected utility of the incumbent for a given signal $s$ and decision $d$ is

$$
\begin{aligned}
\mathbf{E} U^{i}(s, d) \equiv & X_{1}+1 \cdot \boldsymbol{I}_{s=a, d=A}-L \cdot\left(\boldsymbol{I}_{s=b, d=A}+\boldsymbol{I}_{s=a, d=B}\right) \\
& +0 \cdot \boldsymbol{I}_{s=b, d=B}+e(d)\left[X_{2}+\mu^{s}\right]+(1-e(d)) \Omega \cdot O(d)
\end{aligned}
$$

where

- $X_{t}$ are the rents she derives in period $t$ when in power,

- $\boldsymbol{I}_{E}$ is the dummy equal to 1 if event $E$ is realized, and 0 otherwise,

- $\Omega O(d)$ is the expected benefit she derives when the opponent governs in the second period, with $\Omega$ being the weight the incumbent puts on the social benefit $O(d)$ obtained thanks to the opponent,

- and $e(d)$ is her probability of being reelected.

While it is considered that the Constitution provides incentives for political rulers to care about social welfare when in power, it is not clear whether they will also value social welfare when they are replaced by an opponent. We therefore allow for several configurations. This will turn out to be of significance.

The important feature for qualitative results is whether the incumbent's expected benefit is constant, increasing or decreasing in $O(d)$. To simplify the exposition without affecting qualitative results, we assume proportionality, and model this benefit as equal to $\Omega O(d)$.

Definition 1 (Incumbent motivations) We use the following terminology:

- If $\Omega=0$, the incumbent is 'office-motivated' and cares about social benefit only when in power.

- If $\Omega>0$, the incumbent is 'altruistic' and always values social benefit (as well as the rents derived from being in power). ${ }^{18}$

\subsection{Electoral timeline}

\section{Period 1}

- Nature draws whether the incumbent's past decisions was appropriate and should be continued, or not. The incumbent privately and fully learns it $(s)$, and publicly makes a decision $d$.

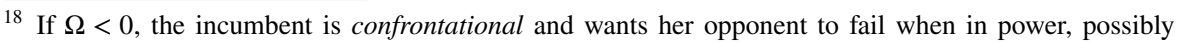
because this will affect other election outcomes, or due to strongly divergent values. We do not discuss this case here as it does not provide interesting additional insights: Being confrontational reinforces the desire to be re-elected. Computations for this case are available from the authors upon request.
} 
- Voters only observe the incumbent's decision $d$ and revise their beliefs about the incumbent.

- The election takes place between the incumbent and an opponent. ${ }^{19}$

\section{Period 2}

- The winner of the election implements her policy.

\section{Voting strategy and equilibrium characteristics}

\subsection{The independent vote and conformism}

An independent voter cares for electing an able politician. Conformism provides an additional reward $W$ if the independent voter votes for the winner. This reward is obtained with certainty when he votes for the incumbent as he is pivotal, but only with probability $1-p$ if he votes for the opponent. This is a crucial way in which conformism and incumbency advantage interact.

- The independent voter's choice.

An independent voter's utility, in equilibrium $E$, is

$\mu^{E}(d) \cdot 1+\left(1-\mu^{E}(d)\right) \cdot 0+W=\mu^{E}(d)+W$ when he votes for the incumbent; $p\left[\mu^{E}(d) \cdot 1+\left(1-\mu^{E}(d)\right) \cdot 0\right]+(1-p)\left[\mu^{o} \cdot 1+\left(1-\mu^{o}\right) \cdot 0+W\right]=p \mu^{E}(d)+(1-p)\left[\mu^{o} \cdot 1+W\right]$

when he votes for the opponent, who gets elected with probability $1-p$.

The two gains cannot be equal except for a specific realization of $\mu^{o}$, which happens with null probability and is independent from players' actions. The independent voter is thus never indifferent between the two candidates, and will never play a mixed strategy. His strategy $v(d)$ is a degenerate mixed strategy.

An independent voter thus votes for the incumbent $(v(d)=1)$ if and only if

$$
\begin{aligned}
\mu^{E}(d)+W & \geq p \mu^{E}(d)+(1-p)\left[\mu^{o}+W\right] \\
\Leftrightarrow \hat{\mu}^{E d} & \equiv \mu^{E}(d)+\frac{p}{1-p} W \geq \mu^{o} .
\end{aligned}
$$

The value $\hat{\mu}^{E d}$ plays the role of a "virtual ability" of the incumbent, augmented by conformism. $^{20}$

The probability that the independent voter votes for the incumbent is denoted

$$
G\left(\hat{\mu}^{E d}\right)=G\left(\mu^{E}(d)+\frac{p}{1-p} W\right)=\min \left\{1, \mu^{E}(d)+\frac{p}{1-p} W\right\} .
$$

\footnotetext{
19 There is no abstention (Callander 2008). If there is a tie, the winner is the opponent. We assume that there is no discount factor for simplicity.

${ }^{20}$ We use a slightly different way of denoting these values, compared with the a posteriori belief $\mu^{E}(d)$, on purpose, to help visually differentiate them.
} 


\section{- Conformism advantage}

In the absence of conformism $(W=0)$, an independent voter always votes for the candidate with the highest expected benefit or ability. This is not the case when voters are conformists. Then the condition for the incumbent to be reelected is weaker when $W$ increases, because less favorable beliefs about the incumbent become sufficient for the independent voter to choose her: $\mu^{E}(d)$ only needs to be larger than $\mu^{o}-\frac{p}{1-p} W$.

Definition 2 The incumbent's 'conformism advantage' is $\frac{p}{1-p} W$.

Conformism acts as if the voter's beliefs about the ability of the incumbent were 'augmented', improved. This conformism advantage is independent from policies. Conformism and assessment of capabilities are fully independent from the point of view of voters. Conformism advantage is amplified by both incumbency advantage $p$ and the strength of the desire to win, $W$. Moreover, each of these two variables has a multiplicative effect on the other variable's impact: An increase in $p$ increases the marginal impact of $W$ on the conformism advantage, and vice-versa.

\section{- Reelection probability}

The overall probability of the incumbent being reelected is the sum of the probability that the incumbent's partisans are a majority, plus the complementary probability times the probability that the independent voter selects the incumbent:

$$
e(d)=p+(1-p) \cdot \min \left\{1 ; \mu^{E}(d)+\frac{p}{1-p} W\right\}=\min \left\{1 ; p(1+W)+(1-p) \mu^{E}(d)\right\} .
$$

Definition 3 (Winning threshold) Let $W^{1}(d)$ be the smallest level of conformism such that the incumbent is reelected with probability 1 when she takes decision $d$, given the ensuing voters' beliefs $\mu^{E}(d), d \in\{A, B\}: W^{1}(d) \equiv \frac{1-p}{p}\left(1-\mu^{E}(d)\right)$.

Because the desire to win and the incumbency advantage interact in the conformism advantage, this winning threshold decreases in $p$. It also decreases in voters' perception about the incumbent's ability $\left(\mu^{E}(d)\right)$ as voters are more willing to elect an incumbent they perceive to be adequate anyway.

When $\hat{\mu}^{E d}=\mu^{E}(d)+\frac{p}{1-p} W<1$, conformism advantage increases the probability of reelection by exactly $p W$. When conformism is so strong that $\mu^{E}(d)+\frac{p}{1-p} W \geq 1$, that is: $W \geq W^{1}(d)$, for a decision $d$, the incumbent is certain to be reelected when she takes that decision; a further increase in $W$ then has no additional impact. 


\subsection{The second-period welfare generated by an opponent}

The expected social benefit generated by an opponent is conditional on her being elected against an incumbent whom voters judge as if she had an average ability $\hat{\mu}^{E d}$ :

If $\hat{\mu}^{E d} \geq 1$, the opponent cannot be elected. If $1 \geq \hat{\mu}^{E d}>0$, we have $O(d) \equiv \mathbf{E}\left[\mu^{o} \mid \mu^{o}>\hat{\mu}^{E d}\right]$. Given that $\mu^{o}$ follows a uniform distribution, the independ-

$$
\begin{gathered}
\text { ent voter's } \quad \begin{array}{l}
\text { belief } \quad \text { about the } \\
\mathbf{E}\left[\mu^{o} \mid \mu^{o}>\hat{\mu}^{E d}\right]=\frac{1}{1-\hat{\mu}^{E d}}\left[\int_{\hat{\mu}^{E d}}^{1} x g(x) d x\right]=\frac{1}{2}\left(1+\hat{\mu}^{E d}\right) . \text { Thus, } \\
O(d)=\frac{1+\hat{\mu}^{E d}}{2} .
\end{array}
\end{gathered}
$$

The larger the perceived 'augmented' capabilities of the incumbent, the larger the capabilities of an opponent who manages to get elected.

\subsection{Socially efficient and pandering equilibria}

We contrast two pure-strategy equilibria. Equilibrium $\mathbf{S}$ is socially efficient, and fully separating with respect to past policy's success $(s)$. Equilibrium $\mathbf{P}$ is an inefficient, pooling equilibrium that corresponds to inefficient persistence ('pandering', $d=C$ ), whatever the incumbent's information. A mixed-strategy equilibrium can exist and is described in the Appendix. This mixed-strategy equilibrium is a semiseparating equilibrium in which only the 'bad type' of incumbent (an incumbent who has observed signal $s=b$ ) plays a mixed strategy, and mixes between $A$ and $B$.

- The separating equilibrium

Equilibrium $\mathbf{S}$ is characterized by

$$
\left\{[d(a)=A, d(b)=B],[v(A), v(B)],\left[\mu^{S}(A)=\mu^{a}, \mu^{S}(B)=\mu^{b}\right]\right\},
$$

where the revised beliefs of an independent voter, $\mu^{S}(A)$ and $\mu^{S}(B)$ are 'accurate' in the sense that the information available to the incumbent $(s)$ is revealed and leads to Bayesian updating; And $[v(A), v(B)]$ are the voting decisions that maximize the voter's utility given beliefs updating (Fig. 1).

- The pooling equilibrium

In equilibrium $\mathbf{P}$, the incumbent hides her negative information by always choosing $A$ even if it is not appropriate, so there is no learning along the equilibrium path: The posterior belief about the incumbent when observing $A, \mu^{P}(A)$, equals the prior $\mu$.

Choosing the 'bad news'-policy $B$ is an out-of-equilibrium move for which we cannot derive beliefs using Bayes' rule. We apply the Intuitive Criterion to refine the pooling equilibria (Cho and Kreps 1987) ${ }^{21}$ An incumbent who has received the

\footnotetext{
${ }^{21}$ In the seminal signaling model by Spence (1973), applying the Intuitive Criterion eliminates all pandering equilibria. This is not the case in our context because the Spence - Mirrlees, 'sorting' condition is not met for all parameter configurations. The $a$-type gets a higher utility, if elected, than a $b$-type; However making decision $A$ can, or not, provide a higher gain to a $b$-type incumbent, via: the increase in re-election probability. So the two types of incumbents may not be 'sorted' according to the strength of
} 
$a$-signal cannot find it optimal to pick decision $B$. We therefore assume that if the incumbent chooses $B$, voters updates their belief about the incumbent to $\mu^{S}(B)=\mu^{b}$ (as if the incumbent was playing according to $\mathbf{S}$ ). Our results however apply to any out-of-equilibrium belief $\mu^{o o e}$ such that policy $B$ is perceived as bad news on the incumbent (i.e.: such that $\mu^{\text {ooe }}<\mu$ ) (Fig. 2). ${ }^{22}$

$\mathbf{P}$ is characterized by

$$
\left\{[d(a)=A, d(b)=A],[v(A), v(B)],\left[\mu, \mu^{S}(B)=\mu^{b}\right]\right\}
$$

and is a pooling equilibrium. In this equilibrium inefficient policy persistence arises, as the incumbent never repeals a failing policy before the election date.

Since $\mu^{S}(A)>\mu>\mu^{S}(B)$, the 'augmented beliefs' (expected benefit plus conformism advantage) are ranked as follows: $\hat{\mu}^{S A} \geq \hat{\mu} \geq \hat{\mu}^{S B}$.

- The mixed-strategy, semi-separating equilibrium

In the mixed-strategy equilibrium (M) of this game, the incumbent chooses policy $A$ when she receives signal $a$, and chooses $B$ with probability $\delta$ when she receives signal $b$. So the M-equilibrium is a semi-separating equilibrium where the 'bad' type of incumbent mimics the 'good' type with a positive probability $\delta$ (cf. Appendix). Associated beliefs are $\left(\mu^{M}(A), \mu^{M}(B)\right)$, that are revised according to Bayes' rule. Because this mixed-strategy equilibrium involves mathematical complexity for limited additional insight, its study is relegated to the Appendix (Fig. 3).

\section{Conformism and policy choices}

We consider in this section the standard case in which a politician cares for social surplus only when in office $(\Omega=0)$. The general case is presented in Sect. 6 and detailed in the Appendix.

\subsection{The socially efficient equilibrium $S$ with $\Omega=0$}

In order for an $\mathbf{S}$-equilibrium to exist, the incentive conditions that follow must be met. They ensure that the incumbent's decision $d$ fully reveals the success of the implemented policy:

Footnote 21 (continued)

their incentive to make decision $A$ rather than $B$. This is why the Intuitive Criterion selects among possible out-of-equilibrium beliefs in a pooling equilibrium but does not eliminate this type of equilibrium.

22 One needs simply to replace $\mu^{P}(B)$ by $\mu^{o o e}$ in formulas that relate to the $\mathbf{P}$ equilibrium. This creates only quantitative changes, except for the equality between two sets of parameters, where the impact of our assumption is discussed in the text. Assuming $\mu^{\text {ooe }}=\mu$ corresponds to the assumption of 'passive beliefs', which is frequent in a number of games but unrealistic in ours: The negative impact on voters' beliefs associated to a given policy (here $B$ ) is indeed the crucial reason why the incumbent may consider a pooling equilibrium in the first place. We show below how assuming passive beliefs would destroy the incentive to pander. 


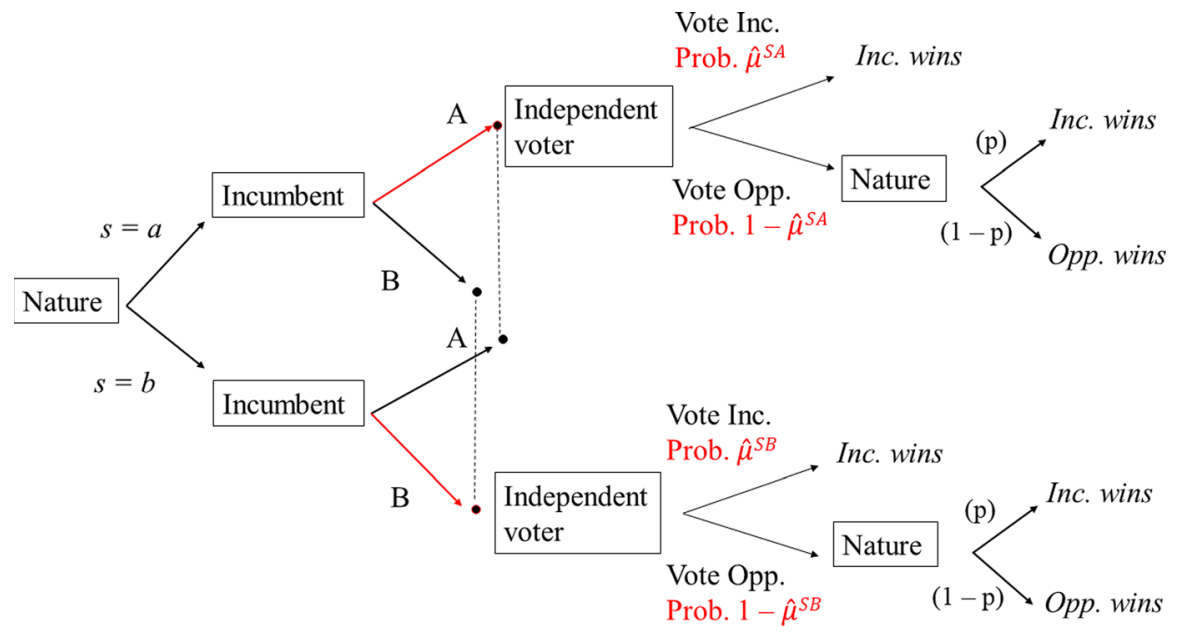

Fig. 1 The separating (S) equilibrium

- If the incumbent observes good news, $a$, she prefers the congruent policy $A$. This holds if and only if: $\left.\left(X_{1}+1\right)+p\left(X_{2}+\mu^{a}\right)\right)+(1-p)\left[G\left(\hat{\mu}^{S A}\right)\left(X_{2}+\mu^{a}\right)\right]$ $\geq\left(X_{1}+0\right)+p\left(X_{2}+\mu^{a}\right)+(1-p)\left[G\left(\hat{\mu}^{S B}\right)\left(X_{2}+\mu^{a}\right)\right]$. This condition simplifies into the following inequality that is always satisfied:

$$
1+(1-p) \cdot\left[G\left(\hat{\mu}^{S A}\right)-G\left(\hat{\mu}^{S B}\right)\right] \cdot\left(X_{2}+\mu^{a}\right) \geq 0 .
$$

Choosing a 'good news'-policy $(A)$ when it is congruent with the private signal increases both reelection chances and social welfare. So there are no incentives to choose policy $B$.

- If the incumbent observes 'bad news' $b$, she prefers to choose the congruent policy $B$. This holds if and only if $\left(X_{1}+0\right)+p\left(X_{2}+\mu^{b}\right)+(1-p)\left[G\left(\hat{\mu}^{S B}\right)\left(X_{2}+\mu^{b}\right)\right]$ $\geq\left(X_{1}-L\right)+p\left(X_{2}+\mu^{b}\right)+(1-p)\left[G\left(\hat{\mu}^{S B}\right)\left(X_{2}+\mu^{b}\right)\right]$. It simplifies into

$$
L \geq(1-p)\left[G\left(\hat{\mu}^{S A}\right)-G\left(\hat{\mu}^{S B}\right)\right] \cdot\left(X_{2}+\mu^{b}\right) \quad(I C)^{S}
$$

This condition is met if the loss $L$ caused by continuing the policy more than offsets the associated gain in reelection probability, given the rents from being in power $\left(X_{2}\right)$ and the expected welfare generated when in power $\left(\mu^{b}\right)$.

In the absence of conformism $(W=0)$, the incumbent is never sure of being reelected, since $p<1$. With conformism however, as shown in Table 1 , there are sets of parameters for which the incumbent is sure to be reelected if she chooses the 'good news'-policy $A$. She may even be reelected for sure whatever her decision, when the desire for conformity is very strong and the incumbency advantage is large enough.

We distinguish three cases, defined by the minimum conformism levels that ensure reelection for a given decision (given that beliefs in the separating equilibrium are $\mu^{S}(A)=\mu^{a}$ and $\left.\mu^{S}(B)=\mu^{b}\right)$ : 


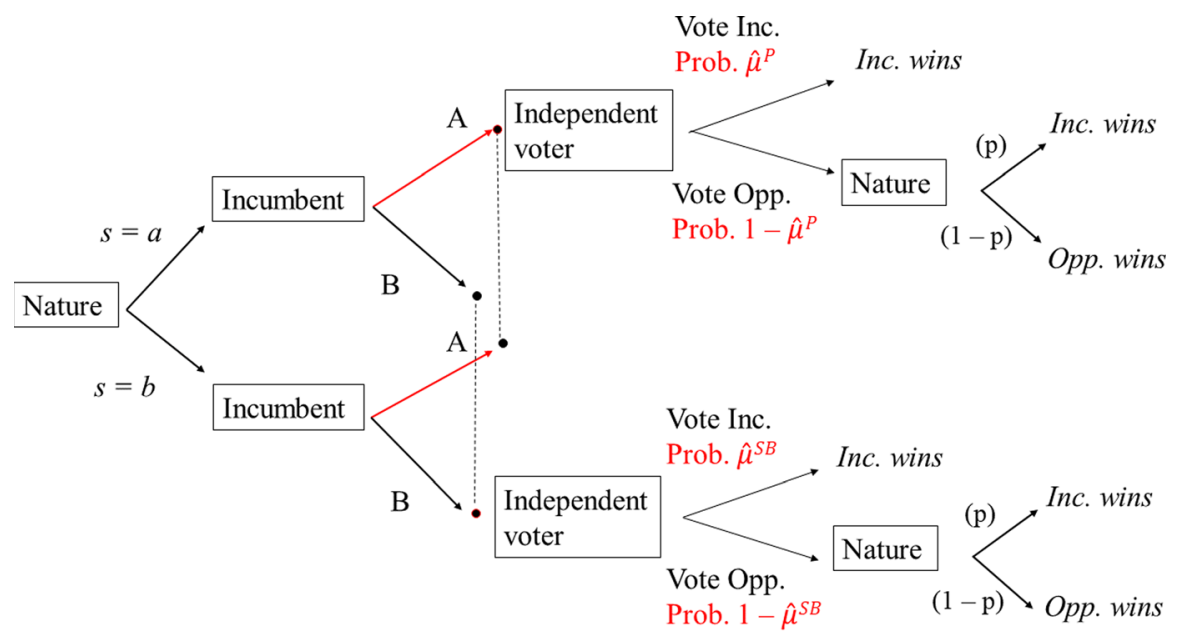

Fig. 2 The pooling (P) equilibrium

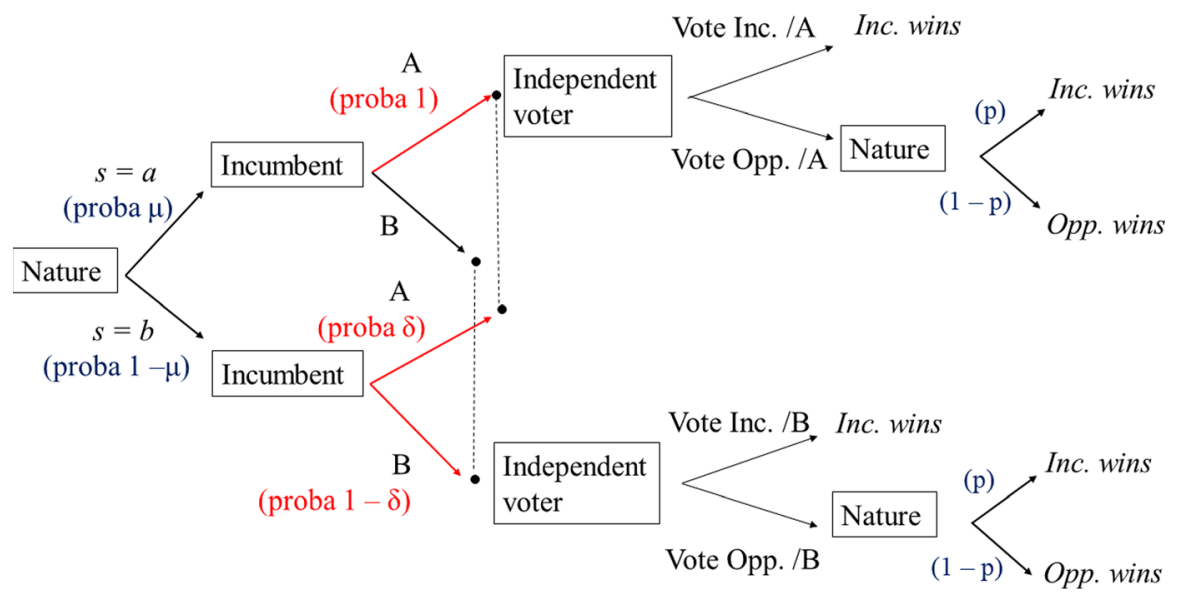

Fig. 3 The mixed-strategy, semi-separating, (M) equilibrium

$$
W^{1}(A)=\frac{1-p}{p}\left(1-\mu^{a}\right) \text { and } W^{1}(B)=\frac{1-p}{p}\left(1-\mu^{b}\right)
$$

(S1) Strong conformism: If $W \geq W^{1}(B)$, the incumbent is sure to be reelected whatever her policy choice.

(S2) Intermediate conformism: If $W^{1}(A)<W<W^{1}(B)$, an incumbent is sure to be reelected only if she chooses the 'good news' policy $A$.

(S3) Weak conformism: If $0 \leq W \leq W^{1}(A)$, the incumbent's probability of being reelected is lower than 1 whatever her policy. 
Table 1 Re-election probabilities in the $\mathbf{S}$ equilibrium

\begin{tabular}{lllll}
\hline Case \# & Conformism $W$ & $\begin{array}{l}\text { Proba. if } \\
d=A G\left(\hat{\mu}^{S A}\right)\end{array}$ & $\begin{array}{l}\text { Proba. if } \\
d=B G\left(\hat{\mu}^{S B}\right)\end{array}$ & $\begin{array}{l}\text { Impact on } \\
(I C)_{\Omega=0}^{S} G\left(\hat{\mu}^{S A}\right)-G\left(\hat{\mu}^{S B}\right)\end{array}$ \\
\hline Case $S 1$ & $W \geq W^{1}(B)$ & 1 & 1 & 0 \\
Case $S 2$ & $W^{1}(B)>W \geq W^{1}(A)$ & 1 & $\mu^{b}+\frac{p}{1-p} W$ & $1-\mu^{b}-\frac{p}{1-p} W$ \\
Case $S 3$ & $W^{1}(A)>W \geq 0$ & $\mu^{a}+\frac{p}{1-p} W$ & $\mu^{b}+\frac{p}{1-p} W$ & $\mu^{a}-\mu^{b}$ \\
\hline
\end{tabular}

The impact on re-election of switching from decision $d=B$ to decision $d=A$ is given by the difference in the last column of Table 1 .

Lemma 1 The gain in reelection probability associated with choosing A rather than the 'bad news' policy $B$ does not depend on conformism except when it is intermediate (Case S2).

For strong conformism (Case $S 1$ ), because the incumbent's decision does not affect her reelection probability, she is better off making the efficient choice. The conditions for $\mathbf{S}$ to exist are thus always met, $(I C)_{\Omega=0}^{S}: \frac{L}{1-p} \geq 0$.

For intermediate conformism (Case $S 2$ ), reelection is ensured if the incumbent chooses $d=A$, but depends on the strength of conformism if she chooses $d=B$. Constraint $(I C)_{\Omega=0}^{S}$ then directly depends on $W$ and writes as

$$
L \geq(1-p)\left[1-\frac{p}{1-p} W-\mu^{S}(B)\right]\left[X_{2}+\mu^{b}\right] .
$$

For weak conformism (Case $S 3$ ), reelection is never certain. Constraint $(I C)_{\Omega=0}^{S}$ is

$$
L \geq(1-p)\left[\mu^{a}-\mu^{b}\right]\left[X_{2}+\mu^{b}\right] .
$$

Thus weak conformism plays no direct role in the incentive of the incumbent to choose congruent policies.

To sum up, an increase in $W$ makes incentive constraints in $\mathbf{S}$ (weakly) less stringent for two reasons: (i) because it may lead to reaching a new threshold, and (ii) because it has a continuous impact on incentives when $W$ lies in the intermediate range (Case $S 2$ ).

Detailed proofs are in Appendix A.3. The above results yield Proposition 1 on the conditions for a separating equilibrium and on the impact of more desire for conformity.

Proposition 1 (The separating equilibrium) When $\Omega=0$ ("office-motivated" incumbent), the separating $\mathbf{S}$-equilibrium exists if and only if the incumbent has incentives to choose the congruent policy $B$ when her signal is $b$. 
Case $S 1 \quad\left[W \geq \frac{1-p}{p}\left(1-\mu^{b}\right)\right]$. For strong conformism, $\mathbf{S}$ always exists.

Case $S 2 \quad\left[\frac{1-p}{p}\left(1-\mu^{a}\right)<W<\frac{1-p}{p}\left(1-\mu^{b}\right)\right]$. For intermediate conformism, $\mathbf{S}$ exists if $L \geq(1-p)\left(1-\mu^{b}-\frac{p W}{1-p}\right)\left(X_{2}+\mu^{b}\right)$. Increases in $W$ continuously make $\mathbf{S}$ more likely to exist.

Case $S 3 \quad\left[0 \leq W<\frac{1-p}{p}\left(1-\mu^{a}\right)\right]$. For weak conformism, $\mathbf{S}$ exists if $L \geq(1-p)\left(\mu^{a}-\mu^{b}\right)\left(X_{2}+\mu^{b}\right)$. This is the most stringent constraint for $\mathbf{S}$ to exist, and it does not depend on $W$.

A higher $W$ facilitates meeting the incentive constraint. ${ }^{23}$ The fundamental reason for this impact of conformism on the emergence of the separating equilibrium is that it lessens the cost (in terms of re-election chances) of following a 'bad news' policy. The incumbent has thus more incentives to choose the most efficient policy.

Corollary 1 More conformism makes it more likely than an equilibrium exists where the incumbent makes efficient choices.

Note that, as discussed in Sect. 5, this does not guarantee that conformism leads to higher social welfare.

\subsection{The pooling equilibrium $P$ with $\Omega=0$}

Let us now consider the pooling ("pandering") equilibrium in which an incumbent hides unfavorable news $(b)$ by choosing action $A$, as she does when in the favorable state $(a)$.

In order for a $\mathbf{P}$-equilibrium to exist, the following incentive conditions must be met:

- The incumbent prefers the congruent policy under signal $a$. This holds if and only if ${ }^{24} 1+(1-p) \cdot\left[G(\hat{\mu})-G\left(\hat{\mu}^{S}(B)\right)\right] \cdot\left(X_{2}+\mu^{a}\right) \geq 0$, which is always satisfied.

- The incumbent must also prefer policy $A$ under signal $b$ although it is not congruent. Given the equilibrium beliefs $\mu$ and out-of-equilibrium beliefs $\mu^{S B}$, this is preferred by the incumbent if and only if $\left(X_{1}-L\right)+p\left(X_{2}+\mu^{b}\right)+(1-p)\left[G(\hat{\mu})\left(X_{2}+\mu^{b}\right)\right] \geq X_{1}+0+p\left(X_{2}+\mu^{b}\right)+(1-p)\left[G\left(\hat{\mu}^{S B}\right)\left(X_{2}+\mu^{b}\right)\right]$, which simplifies into

$$
L \leq(1-p)\left[G(\hat{\mu})-G\left(\hat{\mu}^{S B}\right)\right]\left[X_{2}+\mu^{b}\right] \quad(I C)_{\Omega=0}^{P} .
$$

\footnotetext{
$\overline{23}$ Note that in case $\mathrm{S} 3, W<\frac{1-p}{p}\left(1-\mu^{a}\right)$, which implies that $\mu^{a}-\mu^{b}>1-\mu^{b}-\frac{p W}{1-p}$ : The condition for the incentive constraint to be met is stricter than if it remained the same as in case S2.

${ }^{24}$ Before simplification the condition writes as: $\left(X_{1}+1\right)+p\left(X_{2}+\mu^{a}\right)+(1-p)\left[G(\hat{\mu})\left(X_{2}+\mu^{a}\right)\right]$ $\geq\left(X_{1}+0\right)+p\left(X_{2}+\mu^{a}\right)+(1-p)\left[G\left(\hat{\mu}^{S}(B)\right)\left(X_{2}+\mu^{a}\right)\right]$.
} 
On a technical side, under the assumption of passive beliefs (which is eliminated by the Intuitive Criterion), this condition could not be met: Choosing policy $B$ would not be considered 'bad news' and there would be no reason for the incumbent to avoid it. ${ }^{25}$

As in the $\mathbf{S}$ equilibrium, we can distinguish three cases, that correspond to different expressions of the reelection probabilities when the independent voter is pivotal.

We define $W^{1 P} \equiv \frac{1-p}{p}(1-\mu)$ as the minimum conformism level ensuring reelection with probability 1 , given the voters' beliefs $(\mu)$ in the pooling equilibrium after observing the equilibrium decision $A .{ }^{26}$ The cases are summarized in Table 2.

In case $P 1$ [Strong conformism], the incumbent is sure to get elected whatever her policy. There is then no incentive to distort policy choices away from efficiency and $\mathbf{P}$ does not exist. The conditions for this case corresponds exactly to the one under which the incumbent strictly prefers choosing efficient policies in the $\mathbf{S}$ equilibrium (cases $S 1$ ) and $P 1$ ) are defined identically). ${ }^{27}$

The pooling equilibrium $\mathbf{P}$ cannot arise: Strong conformism eliminates pandering.This result is very strong: It does not depend on the size of the benefits (1) and losses $(L)$ associated with the chosen policies.

If we assume different out-of-equilibrium beliefs than $\mu^{b}$, the definition of strong conformism has to be slightly adjusted and cases $S 1$ and $P 1$ do not perfectly overlap $^{28}$.

In case $P 2$ [Intermediate conformism], the incumbent is sure to get reelected when she runs policy $A$ but not if she plays the out-of-equilibrium strategy $B$. The incentive condition $(I C)_{\Omega=0}^{P}$ is then

$$
L<(1-p)\left[1-\frac{p}{1-p} W-\mu^{b}\right]\left(X_{2}+\mu^{b}\right) .
$$

When $W$ increases, the incentive condition is more difficult to satisfy.

In case $P 3$ [Weak conformism]', the incentive condition $(I C)_{\Omega=0}^{P}$ that ensures that $\mathbf{P}$ exists, becomes

$$
L \leq(1-p)\left[\mu-\mu^{b}\right]\left(X_{2}+\mu^{b}\right)
$$

\footnotetext{
${ }^{25}$ When beliefs do not react to the incumbent's decision, $\hat{\mu}^{S B}$ has to be replaced by $\hat{\mu}$. The right-hand side becomes null $(G(\hat{\mu})-G(\hat{\mu})=0)$, and we cannot have $\frac{L}{1-p} \leq 0$. Choosing the 'bad news' policy $B$ does not degrade beliefs (nor reelection chances); but it enables to avoid the loss $L$ due to a non congruent policy. It is therefore always a better strategy. In other words, if we assumed passive beliefs, the negative signal associated to policy $B$ would be assumed away, and the pandering equilibrium $\mathbf{P}$ could not exist.

26 If the incumbent played the out-of-equilibrium strategy $B$, the threshold would be determined by the out-of-equilibrium beliefs, and equal to $\frac{1-p}{p}\left(1-\mu^{o o e}\right)$ given our assumption that $\mu^{S}(B)=\mu^{o o e}$.

27 Condition $(I C)_{\Omega=0}^{P}$ is then equivalent to $L \leq 0$, which is not possible.

28 With out-of-equilibrium beliefs $\mu^{\text {ooe }}$ when policy $B$ is chosen, the $\mathbf{S}$ equilibrium is the only pure-strategy equilibrium that exists when $W \geq \frac{1-p}{p}\left[1-\mu^{o o e}\right]$.
} 
The conditions for the existence of the inefficient $\mathbf{P}$-equilibrium are summarized in Proposition 2

Proposition 2 (The pooling equilibrium) When the incumbent is office-motivated $(\Omega=0)$, the existence of a pooling equilibrium $\mathbf{P}$ is determined by the incentive constraint under the bad news signal $(b)$.

Case $P 1 \quad\left[W \geq \frac{1-p}{p}\left(1-\mu^{b}\right)\right]$. For strong conformism, pooling can never arise as an equilibrium outcome.

Case $P 2 \quad\left[\frac{1-p}{p}(1-\mu) \leq W<\frac{1-p}{p}\left(1-\mu^{b}\right)\right]$. For intermediate conformism, $\mathbf{P}$ exists if $L<(1-p)\left[1-\frac{p}{1-p} W-\mu^{b}\right]\left(X_{2}+\mu^{b}\right)$. Increases in $W$ continuously make $\mathbf{P}$ less likely to arise.

Case $P 3 \quad\left[W<\frac{1-p}{p}(1-\mu)\right]$. For weak conformism, $\mathbf{P}$ exists if $L \leq(1-p)\left[\mu-\mu^{b}\right]\left(X_{2}+\mu^{b}\right)$. This is the least stringent constraint for $\mathbf{P}$ to arise and it does not depend on $W$.

The following proposition is a corollary from Propositions 1 and 2:

Proposition 3 (Conformism and equilibrium existence) Strong conformism eliminates inefficient policy choices for an office-motivated incumbent: When $W \geq \frac{1-p}{p}\left(1-\mu^{b}\right)$, the $\mathbf{S}$ equilibrium always exists and $\mathbf{P}$ does not exist.

In the special case where A consists in persisting in a policy and B in repealing it, strong conformism eliminates inefficient persistence.

One can note that the result that strong conformism leads to more efficient decisions is in line with the analysis in Maskin and Tirole (2004): If conformism is extremely strong (or if the incumbency advantage of the incumbent is extremely large), the incumbent is always reelected. Her mandate no longer depends on her decisions - as the judge in Maskin and Tirole (2004). Although the mechanism and framework are quite different, a common thread is that being less exposed to election pressure can improve decision-making.

\section{The impact of conformism on social welfare}

The previous section shows how an increase in conformism makes it more likely that the incumbent makes efficient choices, that is: chooses policies congruent with the real state of the world. However this is not enough to conclude that conformism improves social welfare: Social welfare indeed also depends on the quality of the selection of the decision-maker in the second period. 
Table 2 Reelection probabilities in the $\mathbf{P}$ equilibrium

\begin{tabular}{lllll}
\hline Case \# & Conformism $W$ & $\begin{array}{l}\text { Proba. if } \\
d=A G(\hat{\mu})\end{array}$ & $\begin{array}{l}\text { Proba. if } \\
d=B G\left(\hat{\mu}^{S B}\right)\end{array}$ & Impact on $(I C)^{P} G(\hat{\mu})-G\left(\hat{\mu}^{S B}\right)$ \\
\hline Case $P 1$ & $W \geq W^{1}(B)$ & 1 & 1 & 0 \\
Case $P 2$ & $W^{1}(B)>W \geq W^{1 P}$ & 1 & $\mu^{b}+\frac{p}{1-p} W$ & $1-\mu^{b}-\frac{p}{1-p} W$ \\
Case $P 3$ & $W^{1 P}>W \geq 0$ & $\mu+\frac{p}{1-p} W$ & $\mu^{b}+\frac{p}{1-p} W$ & $\mu-\mu^{b}$ \\
\hline
\end{tabular}

We assume that social welfare is the sum of the expected benefits created by the elected politician over the two periods. Given a signal $s$ and a decision $d$, social welfare is:

$$
S W=\mathbf{E}_{s}\left[1 \cdot \boldsymbol{I}_{s=a}+0 \cdot \boldsymbol{I}_{s=b}+e(d) \mu^{s}+(1-e(d)) O(d)\right]
$$

We denote social welfare as a function of the equilibrium case considered (S1, S2, etc.). Details of the computations are in Appendix A.5.

\subsection{Social welfare in a S-equilibrium}

In a separating equilibrium, social welfare is equal to ${ }^{29}$

$$
\begin{aligned}
S W(S 1)= & \mu\left(1+\mu^{a}\right)+(1-\mu) \mu^{b} \\
S W(S 2)= & \mu\left(1+\mu^{a}\right)+(1-\mu) \\
& {\left[\left(p+(1-p)\left(\mu^{b}+\frac{p W}{1-p}\right)\right) \mu^{b}+(1-p) \frac{1}{2}\left(1-\left(\mu^{b}+\frac{p W}{1-p}\right)^{2}\right)\right] } \\
S W(S 3)=\mu & {\left[1+\left(p+(1-p) \hat{\mu}^{S A}\right) \mu^{a}+(1-p) \frac{1}{2}\left(1-\left(\mu^{a}+\frac{p W}{1-p}\right)^{2}\right)\right] } \\
& +(1-\mu)\left[0+\left(p+(1-p) \hat{\mu}^{S B}\right) \mu^{b}+(1-p) \frac{1}{2}\left(1-\left(\mu^{b}+\frac{p W}{1-p}\right)^{2}\right)\right] .
\end{aligned}
$$

\subsection{Social welfare in a P-equilibrium}

For strong conformism (P1), no pooling equilibrium exists. In a pooling equilibrium, social welfare equals:

\footnotetext{
${ }^{29}$ For strong conformism (S1), the incumbent is always reelected and generates an expected welfare that depends on the signal. For intermediate conformism (S2), she is reelected for sure when $s=a$ as she then plays $A$, but not always when $s=b$ (as she then plays $B$ ) in which case the opponent gets reelected with a positive probability and creates expected welfare $\frac{1+\hat{\mu}: S B}{2}$. For weak conformism (S3), reelection is always uncertain.
} 


$$
\begin{aligned}
S W(P 2)= & \mu\left(1+\mu^{a}\right)+(1-\mu)\left(-L+\mu^{b}\right) \\
S W(P 3)= & \mu\left[1+(p+(1-p) \hat{\mu}) \mu^{a}\right]+(1-\mu)\left[-L+(p+(1-p) \hat{\mu}) \mu^{b}\right] \\
& +(1-p) \frac{1}{2}\left(1-\left(\mu+\frac{p W}{1-p}\right)^{2}\right) .
\end{aligned}
$$

For intermediate conformism (P2), the incumbent always gets reelected; for weak conformism (P3), the incumbent, whatever the signal, is reelected only if $W$ and $p$ are large enough ( $\hat{\mu}$ large).

\subsection{The effects of conformism on social welfare}

Conformism has several effects on social welfare:

- A negative effect that arises from the voter's choice, the 'candidate selection effect': An increase in $W$ increases $\hat{\mu}^{S d}$ and $\hat{\mu}$, so the incumbent is reelected too often against a more appropriate opponent, whether the equilibrium is a pooling or separating one.

- Positive effects that arise if conformism changes the equilibrium:

- A positive 'policy selection effect': If, and only if, an increase in $W$ induces a switch from a pooling to a separating equilibrium, then it avoids the loss $L$ from non-congruent decisions in state $b$.

- A positive 'voters information effect': If, and only if, an increase in $W$ induces a switch from a pooling to a separating equilibrium, then it improves voters' information on the incumbent, and it avoids a too frequent reelection of a $b$-incumbent and too rare reelection of a $a$-incumbent (so it improves candidate selection).

The welfare impact of an increase in conformism depends therefore crucially on whether it changes the type of strategy played by the incumbent. Appendix A.5.3. details the impact of a marginal increase in $W$ that leads to moving from an equilibrium configuration to another.

In some cases, increases in $W$ have no effect on decisions (because the equilibrium remains either separating or pooling), but they affect re-election chances. Under separation, marginal increases above $W^{1}(B)$ or above $W^{1}(A)$ change equilibrium configurations, but not the efficiency of decisions, as the equilibrium remains separating. But the incumbent is more often re-elected, although she is less appropriate than the opponent under $\mu<\mu^{o}$. This corresponds to the candidate selection cost of an increase in conformism, in a separating equilibrium. Under pooling, a marginal increase in $W$ above $W^{1 P}$ ensures that the incumbent gets re-elected with probability 1 . This has an ambiguous effect on social welfare as both types of incumbent ('a' or ' $b$ ') are re-elected more often than if conformism was slightly weaker.

In some other cases, increases in $W$ may instead affect the efficiency of decisions, by inducing a switch from a pooling to a separating equilibrium. For instance, a marginal increase in $W$ from under to above $W^{1}(B)$, moves the 
equilibrium from $\mathrm{P} 2$ to $\mathrm{S} 1$. In both cases, the incumbent is always re-elected so no candidate selection effect arises. But the switch would create a welfare gain of $S W(S 1)-S W(P 2)=(1-\mu) L>0$, since the incumbent would now select a congruent decision. Moving from P3 to S2 would both avoid some losses from pandering and improve candidate selection.

Proposition 4 (Conformism and social welfare) Conformism has an ambiguous impact on social welfare.

- A marginal increase in $W$ inducing a move from a S2-type equilibrium to a S1-type one, creates a welfare loss (candidate selection loss).

- A marginal increase in $W$ inducing a move from a P3-type equilibrium to a P2-type one, has an ambiguous impact on welfare.

- A marginal increase in $W$ inducing a move from a P2-type equilibrium to a $\mathrm{S} 1$-type one, creates a welfare gain (decision selection efficiency gain).

\section{The case of an altruistic incumbent, $\Omega>0$}

This section briefly presents the results when the incumbent is 'altruistic' $(1>\Omega>0)$, in the sense that she cares about private benefits, but also about social welfare, even when not in power. Detailed results and proofs are in Appendices A.3. and A.4.

Note that we do not assume that the weight on social welfare is the same when in power (weight 1) and when out of power (weight $\Omega$ ). This is because being in power implies specific additional incentives provided by the Constitution and by reputation concerns concerns (as traditionally assumed in the literature).

While the degree of altruism of an incumbent can depend on personality, some mandates are more conducive to such altruism: The mayor of a small municipality may have strong chances of still residing in the city if her opponent gets elected, and of being directly impacted by the quality of the new mayor's choices. ${ }^{30}$

\subsection{The intuition for a non-monotonic impact of conformism}

Contrary to the case of an office-motivated incumbent, more conformism can lead to more inefficiency in the policy choices of the incumbent when she is altruistic. This effect arises from the impact of $W$ on her reelection chances.

An altruistic incumbent partly internalizes the costs of being reelected against an opponent who would be better able, on average, to generate welfare. The stronger the desire for conformity, the more likely it is that the incumbent gets elected although the opponent would have generated more welfare.

\footnotetext{
${ }^{30}$ In some cases, one may argue that in a long-term perspective and for very ideological elections, an incumbent may want her opponent to fail in her choices, so as to ensure that the incumbent's party will be back in power in a future period. We abstract from this last case $(\Omega<0)$.
} 
Compared with policy $B$, choosing policy $A$ makes it more likely that the incumbent gets reelected although the opponent would actually have raised more surplus. Policy $A$ therefore involves losing in expectation a higher potential benefit (because of the non-election of the opponent) than policy $B$. Indeed, if the opponent does not get elected despite the 'bad news' associated to $B$, her perceived ability $\mu^{o}$ must be low. An altruistic incumbent has therefore lower incentives to hide bad news by choosing $A$ when her signal is $b .{ }^{31}$

This effect makes the incentive condition in a separating equilibrium easier to satisfy and the incentive condition in a pooling equilibrium more difficult to satisfy.

However, an increase in $W$ does not always reinforce this socially efficient effect: When $W$ increases,

- the probability that the opponent is of higher ability that the incumbent increases,

- but the opponent has fewer chances to be elected even if the incumbent chooses policy $B$.

The two effects play in opposite directions, and each one dominates in a different configuration (cf. Appendices A.3. and A.4.). At the extreme, when $W$ gets so large that the incumbent is reelected in all cases (strong conformism, cases S1 and P1), altruism no longer plays any role.

In the main text, we provide only the conditions for the incentive constraint under the 'bad news' signal $b$ to be met, in a separating and in a pooling equilibrium. Contrary to the case with an office-motivated incumbent, the incentive constraint for signal $a$ is not automatically satisfied with $\Omega>0$. This is because of the additional effects described above. However for reasonable parameter values, the incumbent's desire to be in power is strong enough so that the relevant constraint is still the constraint that applies under 'bad news' (Appendices A.3 and A.4 provide the analysis for both 'bad news' and 'good news' signals).

\subsection{The socially efficient equilibrium $S$ with $\Omega>0$}

Proposition 5 Consider an 'altruistic' incumbent $(\Omega>0)$.

Case $S 1 \quad\left[W \geq \frac{1-p}{p}\left(1-\mu^{b}\right)\right]$. The separating equilibrium always exists.

Case $S 2 \quad\left[\frac{1-p}{p}\left(1-\mu^{a}\right) \leq W<\frac{1-p}{p}\left(1-\mu^{b}\right)\right]$. For intermediate conformism, the incentive condition for the incumbent to select the congruent policy $B$ when her signal is $b$ is

\footnotetext{
${ }^{31}$ Conversely an altruistic incumbent may have perverse incentives to select $B$ while her signal is $a$, in order to reduce her reelection chances despite a strong desire for conformity from voters. However it seems reasonable to assume that parameters are such that the associated incentive constraint is not relevant.
} 


$$
L \geq(1-p)\left(1-\mu^{b}-\frac{p W}{1-p}\right)\left(X_{2}+\mu^{b}\right)-(1-p) \frac{\Omega}{2}\left[1-\left(\mu^{b}+\frac{p W}{1-p}\right)^{2}\right] .
$$

An increase in Whas an ambiguous effect.

Case $S 3 \quad\left[0 \leq W<\frac{1-p}{p}\left(1-\mu^{a}\right)\right]$. For weak conformism, the incentive condition for the incumbent to select the congruent policy $B$ when her signal is $b$ is

$$
L \geq(1-p)\left(\mu^{a}-\mu^{b}\right)\left(X_{2}+\mu^{b}\right)-(1-p) \frac{\Omega}{2}\left(\mu^{a}-\mu^{b}\right)\left(\mu^{a}+\mu^{b}+2 \frac{p W}{1-p}\right) .
$$

An increase in W makes it easier to satisfy.

\subsection{The pandering equilibrium $P$ with $\Omega>0$}

Proposition 6 Consider an 'altruistic' incumbent $(\Omega>0)$.

Case $P 1 \quad\left[W \geq \frac{1-p}{p}\left(1-\mu^{b}\right)\right]$. For strong conformism, pooling can never arise as an equilibrium.

Case $P 2 \quad\left[\frac{1-p}{p}(1-\mu) \leq W<\frac{1-p}{p}\left(1-\mu^{b}\right)\right]$. For intermediate conformism, the incentive condition for the incumbent to choose $A$ when her signal is $b$ is satisfied if

$$
L \leq(1-p)\left[\left(1-\mu^{b}-\frac{p W}{1-p}\right)\left(X_{2}+\mu^{b}\right)-\frac{\Omega}{2}\left(1-\left(\mu^{b}+\frac{p W}{1-p}\right)^{2}\right)\right] .
$$

An increase in Whas an ambiguous impact.

Case $P 3 \quad\left[W<\frac{1-p}{p}(1-\mu)\right]$. the incentive condition for the incumbent to choose $A$ when her signal is $b$ is satisfied if

$$
\left.L \leq(1-p)\left(\mu-\mu^{b}\right)\left[X_{2}+\mu^{b}\right)-\frac{\Omega}{2}\left(\mu+\mu^{b}+2 \frac{p W}{1-p}\right)\right] .
$$

An increase in $W$ makes the condition easier to satisfy.

An increase in $W$ has a different impact in cases $\mathrm{P} 2$ and P3. In case P2, an increase in $W$ always makes the condition more difficult to satisfy when $\Omega=0$ but not necessarily when $\Omega>0$. This is because it affects differently the election chances of the opponent depending on the decision chosen (under decision $A$, a change in $W$ has 
no impact on the opponent's prospects since she does not get elected anyway). To the contrary in case P3, an increase in $W$ has no impact when $\Omega=0$ but makes the incentive condition easier to satisfy when $\Omega>0$. This is because an increase in $W$ reduces the chances of the opponent whatever the policy choice of the incumbent in that case.

As a corollary to Propositions 5 and 6, we obtain the following result:

Proposition 7 Conformism has a non-monotonic impact on policy efficiency for an altruistic incumbent.

\section{Conclusion}

Our analysis has shown how the signaling motives of an incumbent depend on the degree to which voters wish to be on the winning side. This result holds even though we have considered a set-up in which conformism does not interact with voters' assessment of the incumbent's qualities. The incumbent's signaling motives may drive her to inefficiently select policies that are not adequate to the context, and to continue failing policies. Because the incumbent benefits from an incumbency advantage, a greater desire to be on the winning side makes the incumbent more likely to get reelected. This creates a 'conformism advantage' that benefits the incumbent, and that arises from the interaction between incumbency advantage and conformism.

The desire for 'conformity' has an ambiguous impact on social welfare and efficiency. More conformism induces a better selection of policies by the incumbent, and can (as a consequence) provide a better information to voters about the capabilities of the incumbent. However it leads to re-electing too often the incumbent. Conformism has a non-monotonic impact when the incumbent is 'altruistic' in the sense that she cares about social surplus even when not in power (a feature one may expect to see more in municipal and local elections). Our results are consistent with examples of recent elections under high uncertainty on the future state of the world, under the Covid epidemic. They apply more broadly to contexts in which the state of the world (including the incumbent's ability) is imperfectly known but which candidate is 'best' can depend on the realization of this state.

The effects we highlight depend crucially on the existence of an incumbency advantage. In this respect, media coverage, opinion polls and political advertising may all modify the extent of incumbency advantage, with non-trivial consequences on policy persistence and efficiency. A rise in the proportion of voters who are partisans and are not politically volatile can also reinforce the impact of conformism. 


\section{Appendix}

\section{A.1. Definition of an equilibrium}

\section{A.1.1. The incumbent's strategy}

Let $\delta(s) \in[0,1]$, for $s=a, b$, be the probability that the incumbent who observes signal $s$ chooses policy $A$. For pure strategies, we will use $d(s) \in\{A, B\}$ to denote the decision following a signal $s$. So $d(s)=A$ is equivalent to $\delta(s)=1$, and $d(s)=B$ is equivalent to $\delta(s)=0$.

\section{A.1.2. The voter's strategy}

We denote $v(d) \in[0,1]$ the probability that the independent voter votes for the incumbent when he observes that her decision is $d$. An independent voter cannot be indifferent between voting for the incumbent and voting for the opponent, unless her augmented belief $\left(\hat{\mu}^{d} \equiv \mu(d)+\frac{p}{1-p} W\right)$ on the incumbent is exactly equal to her belief on the opponent $\left(\mu^{o}\right)$. Because the exact value of $\mu^{o}$ is drawn after the incumbent has chosen her strategy, the incumbent cannot play a mixed strategy that induces this equality $\hat{\mu}(d)=\mu^{o}$. So this equality only occurs with a null probability with continuous distributions. The voter's strategy is never stochastic.

The independent voter always prefers to vote for the candidate for which his (augmented) beliefs are the highest. We have:

$$
\begin{aligned}
& V(d)=1 \text { if } \mu^{E}(d)+\frac{p}{1-p} W \geq \mu^{o} \\
& V(d)=0 \text { otherwise }
\end{aligned}
$$

where $\mu^{E}(d)$ are the equilibrium updated beliefs following decision $d$ in equilibrium E.

Lemma 2 The independent voter always plays a pure strategy, which consists in voting for the incumbent if his (equilibrium) augmented beliefs about her are higher than $\mu^{\circ}$, and to vote for the opponent otherwise.

\section{A.1.3. Pure strategies}

A pure strategy profile $[d(a), \quad d(b), \quad(V(d(a)), \quad V(d(b))]$ and a belief $\left(\mu^{E}(C), \mu^{E}(R)\right)$ constitutes a Perfect Bayesian Equilibrium $E$, if the strategies $[d(a), d(b),(V(d(a)), V(d(b))]$ maximize each corresponding player's utility given beliefs $\left(\mu^{E}(C), \mu^{E}(R)\right)$ and the other players' strategies; and beliefs $\left(\mu^{E}(C), \mu^{E}(R)\right)$ are updated using Bayes' rule for strategies $[d(a), d(b),(V(d(a)), V(d(b))]$. 
The incumbent's socially efficient strategy is to choose the policy congruent with the signal. Equilibrium $\mathbf{S}$ is characterized by $\left.[d(a)=A, d(b)=B),(v(A), v(B)),\left(\mu^{S}(A)=\mu^{a}, \mu^{S}(B)=\mu^{b}\right)\right]$.

Conversely, in equilibrium $\mathbf{P}$, the incumbent hides her information by always choosing the 'good news' policy $A$ even though it is inefficient to do so when the signal is $b . \mathbf{P}$ is characterized by $[d(a)=A, d(b)=A),(v(A), v(A)),\left(\mu^{P}, \mu^{b}\right]$ and is a pooling equilibrium. As explained in the text, we assume that the out-of-equilibrium belief when observing $B$ in a pooling equilibrium (in which the incumbent should always play $A$ ) is the same as if the incumbent was playing the separating equilibrium, that it: $\mu^{S}(B)=\mu^{b}$.

In the main text, because we focus on pure strategy equilibria, we do not need the above notations on mixed strategies, and directly use the choice made by the incumbent $(d \in\{A, B\})$ and the corresponding decision of the single representative independent voter.

\section{A.1.4. Mixed strategies}

With mixed strategies, only the incumbent can play according to a non-degenerated strategy (we have seen that the independent voter always prefers to vote either for one candidate or for the other).

In addition, choosing $B$ when the signal is $a$ constitutes both a bad signal to voters (which reduces reelection chances) and a bad decision in terms of welfare generated in the first period. An incumbent who has observed signal $a$ will therefore never play $B$ with a non-null probability.

As a consequence, a mixed-strategy equilibrium is necessarily a semi-separating equilibrium in which

- the incumbent plays $A$ with probability 1 if $s=a$,

- and plays $A$ with probability $\delta$ in $[0,1]$ if $s=b$,

- the independent voter plays $v(d)=1$ if $\mu^{M}(d)+\frac{p}{1-p} W \geq \mu^{o}$ and $v(d)=0$ otherwise,

- where beliefs comes from Bayesian updating: $\mu^{M}(B)=\mu^{b}$ and $\mu^{M}(A)=\frac{\mu^{a}}{\mu^{a}+\mu^{b} \delta}$ (Fig. 4).

\section{A.2. Mixed-strategy equilibrium}

We characterize the mixed-strategy equilibrium for an office-motivated incumbent $(\Omega=0)$ :

Given the voter's strategy and beliefs, the incumbent cannot be reelected when playing $A$ if the mixing probability is such that $\mu^{M}(A)<\mu^{o}-\frac{p}{1-p} W$, that is if $\frac{\mu^{a}}{\mu^{a}+\mu^{b} \delta}<\mu^{o}-\frac{p}{1-p} W$. So she cannot be reelected when playing $A$ if a ' $b$-type' plays $A$ too often, i.e., if $\delta \geq \frac{\mu^{a}}{\mu^{b}}\left[\frac{1}{\mu^{o}-\frac{p}{1-p} W}-1\right]$. Because the mixing probability $\delta$ is chosen 
before the realization of the opponent's type, the incumbent uses expectations to compute her reelection probability depending on the mixing probability.

- After observing signal $b$, the incumbent chooses her mixing probability $\delta$ as follows:

$$
\begin{aligned}
& \max _{\delta}(1-\delta)\left[0+X_{1}+G\left(\mu^{b}+\frac{p W}{1-p}\right)\left(X_{2}+\mu^{b}\right)\right] \\
& \quad+\delta\left[-L+X_{1}+G\left(\frac{\mu^{a}}{\mu^{a}+\mu^{b} \delta}+\frac{p W}{1-p}\right)\left(X_{2}+\mu^{b}\right)\right]
\end{aligned}
$$

We need to distinguish three cases depending on whether $G\left(\mu^{b}+\frac{p W}{1-p}\right)$ and $G\left(\mu^{a}+\frac{p W}{1-p}\right)$ are strictly below 1 or not.

\section{A.2.1. M equilibrium with strong conformism}

Assume that $w$ is large enough so that $\mu^{b}+\frac{p W}{1-p} \geq 1$ and $\mu^{a}+\frac{p W}{1-p} \geq 1$, that is: $W \geq W^{1}(B)$. Then we have $G\left(\mu^{b}+\frac{p W}{1-p}\right)=G\left(\mu^{a}+\frac{p W}{1-p}\right)=1$.

In this case, playing $A$ with probability $\delta$ only generates losses $L$ without changing second-period outcomes (as can be seen from program 5 when replacing probabilities by 1 . The equilibrium value for $\delta$ is the smallest possible: 0 . The equilibrium is the separating one.

Lemma 3 Case (M1) Strong conformism. $\left[W \geq W^{1}(B)\right]$. The mixed-strategy equilibrium cannot exist. The only equilibrium is the separating one $(\delta=0)$.

\section{A.2.2. M equilibrium with intermediate conformism}

Assume that $w$ is intermediate so that $\mu^{b}+\frac{p W}{1-p}<1$ and $\mu^{a}+\frac{p W}{1-p} \geq 1$, that is: $W^{1}(A) \leq W<W^{1}(B)$. Then we have $G\left(\mu^{b}+\frac{p W}{1-p}\right)^{1-p}=\mu^{b}+\frac{p W}{1-p}$ and $G\left(\mu^{a}+\frac{p W}{1-p}\right)=1$. The incumbent's problem is thus

$$
\max _{\delta}(1-\delta)\left[0+X_{1}+\left(\mu^{b}+\frac{p W}{1-p}\right)\left(X_{2}+\mu^{b}\right)\right]+\delta\left[-L+X_{1}+X_{2}+\mu^{b}\right]
$$

The first-order condition writes as

$$
\begin{aligned}
0 & =-\left[X_{1}+\left(\mu^{b}+\frac{p W}{1-p}\right)\left(X_{2}+\mu^{b}\right)\right]+\left[-L+X_{1}+X_{2}+\mu^{b}\right] \\
& =-L+\left(X_{2}+\mu^{b}\right)\left[1-\mu^{b}-\frac{p W}{1-p}\right]
\end{aligned}
$$

This condition is independent from $\delta$ so the solution is bang-bang. The equilibrium is a separating one $(\delta=0)$ is the expression is negative (the objective decrease in $\delta$ ), 


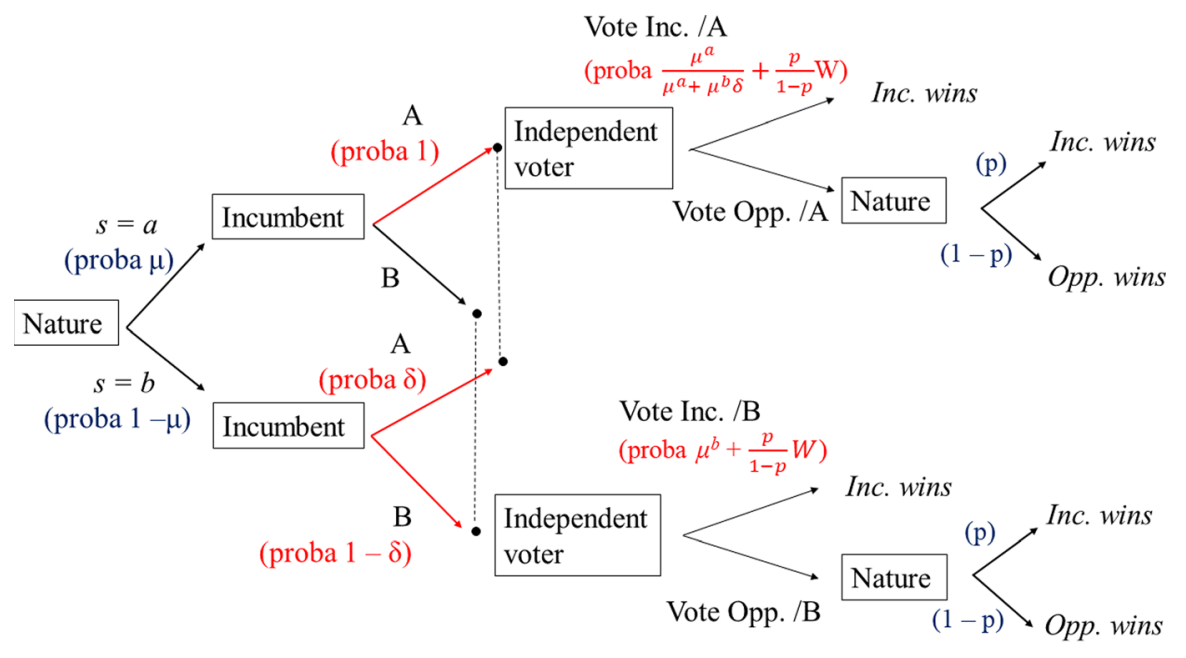

Fig. 4 The mixed strategy (M) equilibrium

i.e., if $\left(X_{2}+\mu^{b}\right)\left[1-\mu^{b}-\frac{p W}{1-p}\right]<L$. It is pooling $(\delta=1)$ if the expression is positive: $\left(X_{2}+\mu^{b}\right)\left[1-\mu^{b}-\frac{p W}{1-p}\right]>L$.

The condition can be expressed in terms of desire for conformity, $W$. Denote $W^{M} \equiv \frac{1-p}{p}\left[1-\mu^{b}-\frac{L}{X_{2}+\mu^{b}}\right]$ The equilibrium is a pooling one if $W<W^{M}$ and a separating one if $W>W^{M}$. Mixed-strategy equilibria cannot exist, except for $W$ exactly equal to $W^{M}$ (in which case there are a multiplicity of equilibria, with $\delta$ in ]0,1[). We neglect this possibility below as it is a mathematical artefact that brings no insight.

Because the analysis is only valid for the case where $W^{1}(A)\left(=\frac{1-p}{p}\left[1-\mu^{a}\right]\right) \leq W<W^{1}(B)\left(=\frac{1-p}{p}\left[1-\mu^{b}\right]\right)$, two cases are possible:

- If $\quad 1-\mu^{a}<1-\mu^{b}-\frac{L}{X_{2}+\mu^{b}}$, that is: if $\mu^{a}-\mu^{b}>\frac{L}{X_{2}+\mu^{b}}$, then $W^{M}=\frac{1-p}{p}\left[1-\mu^{b}-\frac{L}{X_{2}+\mu^{b}}\right]>W^{1}(A)$. So $W^{M}$ does belong to $\left[W^{1}(A), W^{1}(B)[\right.$. The equilibrium is a separating one for $W$ in $\left[W^{M}, W^{1}(B)\right.$ [ and a pooling one for $W$ in $\left[W^{1}(A), W^{M}[\right.$.

- If $\mu^{a}-\mu^{b}<\frac{L}{X_{2}+\mu^{b}}$, then $W^{M}<W^{1}(A)$. For $W \in\left[W^{1}(A), W^{1}(B)[\right.$, the equilibrium is always separating.

Lemma 4 Case M2 Intermediate conformism. $\left[W^{1}(A) \leq W<W^{1}(B)\right]$. Define $W^{M} \equiv \frac{1-p}{p}\left[1-\mu^{b}-\frac{L}{X_{2}+\mu^{b}}\right]$.

- If $\mu^{a}-\mu^{b}<\frac{L}{X_{2}+\mu^{b}}$, then $W^{M}<W^{1}(A)$ and the only equilibrium is the separating one $\mathbf{S}$.

- If $\mu^{a}-\mu^{b}>\frac{L}{X_{2}+\mu^{b}}$, then $W^{M} \in\left[W^{1}(A), W^{1}(B)[\right.$; The equilibrium is 
separating (S) for $W^{M} \leq W<W^{1}(B)$,

pooling $(\mathbf{P})$ for $W^{1}(A) \leq W \leq W^{M}$.

An increase in $W$ makes it more likely that the equilibrium is separating.

\section{A.2.3. M equilibrium with weak conformism}

Assume now that $w$ is small enough so that $\mu^{b}+\frac{p W}{1-p}<1$ and $\mu^{a}+\frac{p W}{1-p}<1$, that is: $W<W^{1}(B)$.

Since $G($.$) is the uniform distribution on [0,1]$, the problem is:

$$
\begin{aligned}
& \max _{\delta}(1-\delta)\left[0+X_{1}+\left(\mu^{b}+\frac{p W}{1-p}\right)\left(X_{2}+\mu^{b}\right)\right] \\
& \quad+\delta\left[-L+X_{1}+\left(\frac{\mu^{a}}{\mu^{a}+\mu^{b} \delta}+\frac{p W}{1-p}\right)\left(X_{2}+\mu^{b}\right)\right]
\end{aligned}
$$

The first-order condition is

$$
\begin{aligned}
0=- & L+\left(X_{2}+\mu^{b}\right) \\
& {\left[\left(\frac{\mu^{a}}{\mu^{a}+\mu^{b} \delta}+\frac{p W}{1-p}\right)-\left(\mu^{b}+\frac{p W}{1-p}\right)+\delta \frac{\partial}{\partial \delta}\left(\frac{\mu^{a}}{\mu^{a}+\mu^{b} \delta}+\frac{p W}{1-p}\right)\right] }
\end{aligned}
$$

The benefit of increasing $\delta$ is that it increases the reelection probability (leading to a gain $X_{2}+\mu^{b}$ ) since $A$ is played more often; Its costs are that it also increases the expected loss from playing $A$ while it is inappropriate, and it downgrades the beliefs of the voter about the incumbent when observing $A$, which reduces the reelection probability.

The first-order condition can be written as:

$$
\begin{aligned}
0 & =-L+\left(X_{2}+\mu^{b}\right)\left[\frac{\mu^{a}}{\mu^{a}+\mu^{b} \delta}-\mu^{b}-\delta \frac{\mu^{a} \mu^{b}}{\left(\mu^{a}+\mu^{b} \delta\right)^{2}}\right] \\
& =-\frac{L}{X_{2}+\mu^{b}}-\mu^{b}+\frac{\mu^{a}}{\mu^{a}+\mu^{b} \delta}-\delta \frac{\mu^{a} \mu^{b}}{\left(\mu^{a}+\mu^{b} \delta\right)^{2}} \\
& =-\left(\frac{L}{X_{2}+\mu^{b}}+\mu^{b}\right)\left(\mu^{a}+\mu^{b} \delta\right)^{2}+\left(\mu^{a}+\mu^{b} \delta\right) \mu^{a}-\delta \mu^{a} \mu^{b} \\
& =-\left(\frac{L}{X_{2}+\mu^{b}}+\mu^{b}\right)\left(\mu^{a}+\mu^{b} \delta\right)^{2}+\mu^{a^{2}}
\end{aligned}
$$

which is equivalent to

$$
0=\delta^{2} \mu^{b^{2}}+2 \delta \mu^{a} \mu^{b}+\mu^{a^{2}}\left(1-\frac{X_{2}+\mu^{b}}{L+\mu^{b}\left(X_{2}+\mu^{b}\right)}\right)
$$


- If $\frac{X_{2}+\mu^{b}}{L+\mu^{b}\left(X_{2}+\mu^{b}\right)}<1$, then all terms in Eq. 6 are positive, so the equality cannot hold for a positive $\delta$. The mixing probability $\delta$ is therefore the boundary value, $\delta=0$, and the equilibrium is separating.

Intuitively, this situation arises when the rents $X_{2}$ from being in power are rather small and the losses $L$ from non-congruent policies are large, so that incentives to pander (i.e., play $A$ after signal $b$ ) are weak.

- Let us consider the case where $\frac{X_{2}+\mu^{b}}{L+\mu^{b}\left(X_{2}+\mu^{b}\right)}>1$ so that an interior solution for $\delta$ can exist. If it does, it solves the second-degree Eq. 6. The discriminant of 6 is $4 \mu^{a^{2}} \mu^{b^{2}}\left(1-\left(1-\frac{X_{2}+\mu^{b}}{L+\mu^{b}\left(X_{2}+\mu^{b}\right)}\right)\right)=4 \mu^{a^{2}} \mu^{b^{2}} \frac{X_{2}+\mu^{b}}{L+\mu^{b}\left(X_{2}+\mu^{b}\right)}>0$. There are two real roots to this equation, one of which is always negative. The relevant root is

$$
\begin{aligned}
& \delta^{*}=\frac{1}{2 \mu^{b^{2}}}\left[-2 \mu^{a} \mu^{b}+\sqrt{4 \mu^{a^{2}} \mu^{b^{2}} \frac{X_{2}+\mu^{b}}{L+\mu^{b}\left(X_{2}+\mu^{b}\right)}}\right] \text { i.e., } \\
& \delta^{*}=\frac{\mu^{a}}{\mu^{b}}\left[-1+\sqrt{\frac{X_{2}+\mu^{b}}{L+\mu^{b}\left(X_{2}+\mu^{b}\right)}}\right]
\end{aligned}
$$

This root must belong to ]0, 1[ to effectively correspond to a semi-separating equilibrium. It it clear that the larger $L$ (losses from playing $A$ instead of $B$ with probability $\delta$ ), the more likely it is that the equilibrium is separating $\left(\delta^{*} \leq 0\right)$.

\section{A.3. Separating equilibrium-Proof of propositions 1 and 5}

\section{A.3.1. Preliminary computations}

- Incumbent's objective. We provide here the proofs for the general case where $\Omega$ may be positive or null. We derive Proposition 1 (case $\Omega=0$ ) and Proposition 5 (case $\Omega>0$ ). Any objective characterized by $\Omega \in[0,1]$ is also covered.

- Expected benefit from the opponent conditional on her winning the election. When the incumbent's decision is $d$ and $1>\hat{\mu}^{E d}>0$ (so that the opponent can be elected with a positive probability), the expected benefit generated by an opponent who wins the election is the conditional expectation $\mathbf{E}\left[\mu^{o} \mid \mu^{o}>\hat{\mu}^{E d}\right]$, with

$$
\mathbf{E}\left[\mu^{o} \mid \mu^{o}>\hat{\mu}^{E d}\right]=\frac{\int_{\hat{\mu}^{E d}}^{1} x g(x) d x}{1-\hat{\mu}^{E d}}=\frac{1+\hat{\mu}^{E d}}{2} .
$$

Note that this conditional expectation depends on what is observed by voters $(d)$ but not on what the incumbent knows (the true state $s$ ).

If $\hat{\mu}^{E d}=1$, since $\mu^{o} \leq 1$, then the opponent can never win. 


\section{A.3.2. Incentive conditions for the S-equilibrium in the favorable state (a)}

Choosing a congruent policy $(A)$ is preferred to the non congruent policy $(B)$ if and only if:

$$
\begin{aligned}
&\left.\left(X_{1}+1\right)+p\left(X_{2}+\mu^{a}\right)\right)+(1-p) G\left(\hat{\mu}^{S A}\right)\left(X_{2}+\mu^{a}\right) \\
&+(1-p)\left(1-G\left(\hat{\mu}^{S A}\right)\right) \Omega \frac{1+\hat{\mu}^{S A}}{2} \\
& \geq\left(X_{1}-L\right)+p\left(X_{2}+\mu^{a}\right)+(1-p) G\left(\hat{\mu}^{S B}\right)\left(X_{2}+\mu^{a}\right) \\
&+(1-p)\left(1-G\left(\hat{\mu}^{S B}\right)\right) \Omega \frac{1+\hat{\mu}^{S B}}{2}(I C)^{S}(a) \\
& \Leftrightarrow 1+L+(1-p)\left[\left(G\left(\hat{\mu}^{S A}\right)-G\left(\hat{\mu}^{S B}\right)\right)\left(X_{2}+\mu^{a}\right)\right. \\
&+\frac{\Omega}{2}\left(\left(1-G\left(\hat{\mu}^{S A}\right)\right)\left(1+\hat{\mu}^{S A}\right)-\left(1-G\left(\hat{\mu}^{S B}\right)\left(1+\hat{\mu}^{S B}\right)\right)\right] \geq 0 .
\end{aligned}
$$

If $\Omega=0$, this condition is always trivially satisfied (the incumbent has no incentive to hide her information when this information is good news).

Lemma 5 Office-motivated incumbent with a favorable signal (a): An increase in W on the incentive condition for a separating equilibrium $\left(I^{S}(a)\right)$ has no impact when $\Omega=0 ;$ The incentive condition is always satisfied.

- This lemma constitutes a first part of the proof of Proposition 1: There is no need to study the incentives of an office-motivated incumbent when the signal is $a$, the only relevant constraint is the one for signal $b, I C^{S}(b)$.

- We study below the incentive condition under signal $a$ for $\Omega>0$, before turning to $I C^{S}(b)$.

- Case S1: $W \geq W^{1}(B)=\left[1-\mu^{b}\right](1-p) / p$. Strong conformism.

When $W \geq W^{1}(B)$, we have $\left.G\left(\hat{\mu}^{S A}\right)\right)=G\left(\hat{\mu}^{S B}\right)=1$, and the incentive condition simplifies into

$$
1+L>0
$$

which is always satisfied. The incumbent is sure to win even with a 'bad news' policy. The degree to which she cares for social welfare when not in power $(\Omega)$ plays no role, since she will always remain in power.

- Case S2: $\left[1-\mu^{b}\right](1-p) / p \leq W<\left[1-\mu^{a}\right](1-p) / p$. Intermediate conformism.

We have $\left.G\left(\hat{\mu}^{S A}\right)\right)=1$ and $G\left(\hat{\mu}^{S B}\right)=\hat{\mu}^{S B}=\mu^{b}+\frac{p W}{1-p}$. The incentive condition writes as 


$$
\begin{aligned}
& 1+L+(1-p) \\
& \quad\left[\left(1-\mu^{b}-\frac{p}{1-p} W\right)\left(X_{2}+\mu^{a}\right)\right. \\
& \left.\quad+\frac{\Omega}{2}\left(0-\left(1+\mu^{b}+\frac{p W}{1-p}\right)\left(1-\mu^{b}-\frac{p W}{1-p}\right)\right)\right] \geq 0,
\end{aligned}
$$

that is (using $\left.(X+y)(x-y)=x^{2}-y^{2}\right)$ :

$$
1+L+(1-p)\left[\left(1-\mu^{b}-\frac{p}{1-p} W\right)\left(X_{2}+\mu^{a}\right)-\frac{\Omega}{2}\left(1-\left(\mu^{b}+\frac{p W}{1-p}\right)^{2}\right)\right] \geq 0 .
$$

Therefore an increase in $W$

- has no impact on the incentive constraint when $\Omega=0$ (it is satisfied anyway)

- makes it easier to satisfy the incentive constraint when $\Omega>0$.

The positive impact of $W$ when the incumbent is altruistic comes from the following channel: An altruistic incumbent has some incentives to select the bad news policy in order to be replaced by the opponent when the latter is "good enough". However an increase in $W$ reduces the chances of the opponent of being elected even if the incumbent chooses the bad news policy. It therefore reinforces the incentives to select the good news policy $(A)$

- Case S3: $W<\left[1-\mu^{b}\right](1-p) / p$. Weak conformism.

In that case, $\left.G\left(\hat{\mu}^{S A}\right)\right)=\hat{\mu}^{S A}=\mu^{a}+\frac{p}{1-p} W$ and $G\left(\hat{\mu}^{S B}\right)=\hat{\mu}^{S B}=\mu^{b}+\frac{p}{1-p} W$. The incentive condition writes as

$$
\begin{aligned}
1+L+ & (1-p)\left(\left(\mu^{a}+\frac{p W}{1-p}\right)-\left(\mu^{b}+\frac{p W}{1-p}\right)\right)\left(X_{2}+\mu^{a}\right) \\
+ & (1-p) \frac{\Omega}{2}\left[\left(1+\mu^{a}+\frac{p W}{1-p}\right)\left(1-\left(\mu^{a}+\frac{p W}{1-p}\right)\right)\right. \\
& \left.-\left(1+\mu^{b}+\frac{p W}{1-p}\right)\left(1-\left(\mu^{b}+\frac{p W}{1-p}\right)\right)\right] \geq 0, \\
\Leftrightarrow \quad & 1+L+(1-p) \\
& \left(\mu^{a}-\mu^{b}\right)\left(X_{2}+\mu^{a}\right) \\
& +\frac{\Omega}{2}\left[\left(1+\mu^{a}+\frac{p W}{1-p}\right)\left(1-\mu^{a}-\frac{p W}{1-p}\right)\right. \\
& \left.\left.-\left(1+\mu^{b}+\frac{p W}{1-p}\right)\left(1-\mu^{b}-\frac{p W}{1-p} W\right)\right]\right] \geq 0 .
\end{aligned}
$$

Using twice that $(x+y)(x-y)=x^{2}-y^{2}$, we can rewrite the incentive condition as 


$$
\begin{aligned}
1+L+(1-p) & {\left[\left(\mu^{a}-\mu^{b}\right)\left(X_{2}+\mu^{a}\right)+\frac{\Omega}{2}\left(1-\left(\mu^{a}+\frac{p W}{1-p}\right)^{2}-\left(1-\left(\mu^{b}+\frac{p W}{1-p}\right)^{2}\right)\right)\right] \geq 0, } \\
\Leftrightarrow & {[1+L+(1-p)} \\
& {\left[\left(\mu^{a}-\mu^{b}\right)\left(X_{2}+\mu^{a}\right)-\frac{\Omega}{2}\left(\left(\mu^{a}+\frac{p W}{1-p}\right)^{2}-\left(\mu^{b}+\frac{p W}{1-p}\right)^{2}\right)\right] \geq 0, } \\
& \Leftrightarrow 1+L+(1-p) \\
& {\left[\left(\mu^{a}-\mu^{b}\right)\left(X_{2}+\mu^{a}\right)-\frac{\Omega}{2}\left(\mu^{a}-\mu^{b}\right)\left(\mu^{a}+\mu^{b}+2 \frac{p W}{1-p}\right)\right] \geq 0 . }
\end{aligned}
$$

For $\Omega>0$, this condition becomes more difficult to satisfy when $W$ increases. This is because an increase in $W$ now reduces the chances of the opponent being elected both for the good news and the bad news policies. The effect is stronger for the good news policy $(A)$ because under that policy, only a very good opponent can be elected, which is desirable from the point of view of an altruistic incumbent (but not of an office-motivated incumbent).

Lemma 6 When $\Omega>0$ ("altruistic" incumbent), an increase in W has a non monotonous impact on the incentive condition for a separating equilibrium under signal a: It makes the condition easier to satisfy for intermediate conformism (S2) but more difficult to satisfy for weak conformism (S3).

\section{A.3.3. Incentive conditions for the S-equilibrium in the unfavorable state (b)}

Choosing a congruent policy $(B)$ is preferred to the non congruent policy $(A)$ if and only if:

$$
\begin{aligned}
X_{1}+ & 0+p\left(X_{2}+\mu^{b}\right)+(1-p) G\left(\hat{\mu}^{S B}\right)\left(X_{2}+\mu^{b}\right) \\
& +(1-p)\left(1-G\left(\hat{\mu}^{S B}\right)\right) \Omega \frac{1+\hat{\mu}^{S B}}{2} \\
\geq & X_{1}-L+p\left(X_{2}+\mu^{b}\right)+(1-p) G\left(\hat{\mu}^{S A}\right)\left(X_{2}+\mu^{b}\right) \\
& +(1-p)\left(1-G\left(\hat{\mu}^{S A}\right)\right) \Omega \frac{1+\hat{\mu}^{S B}}{2} \quad(I C)^{S}(b)
\end{aligned}
$$

This condition writes as

$$
\begin{aligned}
& L+(1-p) \\
& \qquad\left[\left(G\left(\hat{\mu}^{S B}\right)-G\left(\hat{\mu}^{S A}\right)\right)\left(X_{2}+\mu^{b}\right)\right. \\
& \left.\quad+\frac{\Omega}{2}\left(\left(1-G\left(\hat{\mu}^{S B}\right)\right)\left(1+\hat{\mu}^{S B}\right)-\left(1-G\left(\hat{\mu}^{S A}\right)\right)\left(1+\hat{\mu}^{S A}\right)\right)\right] \geq 0 . \quad(I C)^{S}(b)
\end{aligned}
$$

- Case S1: $W \geq W^{1}(B)=\left[1-\mu^{b}\right](1-p) / p$. Strong conformism. 
When $W \geq W^{1}(B)$, we have $G\left(\hat{\mu}^{S A}\right)=G\left(\hat{\mu}^{S B}\right)=1$, and the incentive condition simplifies into $L \geq 0$ which is always satisfied.

- Case S2: $\left[1-\mu^{a}\right](1-p) / p \leq W<\left[1-\mu^{b}\right](1-p) / p$. Intermediate conformism.

We have $G\left(\hat{\mu}^{S A}\right)=1$ and $G\left(\hat{\mu}^{S B}\right)=\hat{\mu}^{S B}=\mu^{b}+\frac{p W}{1-p}$. The incentive condition writes as

$$
\begin{aligned}
& L+(1-p) \\
& {\left[-\left(1-\left(\mu^{b}+\frac{p W}{1-p}\right)\right)\left(X_{2}+\mu^{b}\right)\right.} \\
& \left.+\frac{\Omega}{2}\left(\left(1-\left(\mu^{b}+\frac{p W}{1-p}\right)\right)\left(1+\mu^{b}+\frac{p W}{1-p}\right)-0\right)\right] \geq 0 \\
& \Leftrightarrow \quad L-(1-p)\left(1-\mu^{b}-\frac{p W}{1-p}\right)\left(X_{2}+\mu^{b}\right) \\
& +(1-p) \frac{\Omega}{2}\left[\left(1-\mu^{b}-\frac{p W}{1-p}\right)\left(1+\mu^{b}+\frac{p W}{1-p}\right)\right] \geq 0 \\
& \Leftrightarrow \quad L-(1-p)\left(1-\mu^{b}-\frac{p W}{1-p}\right)\left(X_{2}+\mu^{b}\right) \\
& +(1-p) \frac{\Omega}{2}\left[1-\left(\mu^{b}+\frac{p W}{1-p}\right)^{2}\right] \geq 0 \\
& \Leftrightarrow \quad L \geq(1-p)\left(1-\mu^{b}-\frac{p W}{1-p}\right)\left(X_{2}+\mu^{b}\right) \\
& -(1-p) \frac{\Omega}{2}\left[1-\left(\mu^{b}+\frac{p W}{1-p}\right)^{2}\right] \text {. }
\end{aligned}
$$

When $\Omega=0$, the condition is unambiguously easier to satisfy when $W$ increases. It is satisfied if $L$ is large enough compared to ego rents $X_{2}$.

When $\omega>0$, the incumbent internalizes that if she chooses the congruent decision $(B)$, the opponent has chances to get elected, which is good for social welfare. She is thus more willing to choose the bad news decision. This is reflected by the last term in the incentive constraint, which is positive. However, because a higher $W$ reduces the chances of the opponent even when $B$ is chosen, the above effect (that plays in favor of separation) is weakened when $W$ increases.

Lemma 7 When the signal is unfavorable $(b)$ and conformism is intermediate $\left(\left[1-\mu^{b}\right](1-p) / p \leq W<\left[1-\mu^{a}\right](1-p) / p\right)$, the impact of an increase in $W$ on the incentive to choose the congruent decision $B$

- is strictly positive if $\Omega=0$,

- is ambiguous if $\Omega>0$. 
- Case S3: $W<\left[1-\mu^{a}\right](1-p) / p$. Weak conformism.

In that case, $G\left(\hat{\mu}^{S A}\right)=\hat{\mu}^{S A}=\mu^{a}+\frac{p W}{1-p}$ and $G\left(\hat{\mu}^{S B}\right)=\hat{\mu}^{S B}=\mu^{b}+\frac{p W}{1-p}$. The incentive condition $(I C)^{S}(b)$ writes as

$$
\begin{aligned}
L+ & (1-p)\left[\left(\mu^{b}+\frac{p W}{1-p}\right)-\left(\mu^{a}+\frac{p W}{1-p}\right)\right]\left(X_{2}+\mu^{b}\right) \\
+ & (1-p) \frac{\Omega}{2}\left[\left(1-\left(\mu^{b}+\frac{p W}{1-p}\right)\right)\left(1+\mu^{b}+\frac{p W}{1-p}\right)\right. \\
& \left.-\left(1-\left(\mu^{a}+\frac{p W}{1-p}\right)\right)\left(1+\mu^{a}+\frac{p W}{1-p}\right)\right] \geq 0
\end{aligned}
$$

that is:

$$
\begin{aligned}
& L-(1-p) \\
& \qquad\left(\mu^{a}-\mu^{b}\right)\left(X_{2}+\mu^{b}\right) \\
& \quad+\frac{\Omega}{2}\left(\left(1-\mu^{b}-\frac{p W}{1-p}\right)\left(1+\mu^{b}+\frac{p W}{1-p}\right)\right. \\
& \left.\quad-\left(1-\mu^{a}-\frac{p W}{1-p}\right)\left(1+\mu^{a}+\frac{p W}{1-p}\right)\right] \geq 0,
\end{aligned}
$$

which simplifies (using the same second-degree identity as for the incentive constraint under signal $a$ ) into

$$
\begin{gathered}
L+(1-p)\left[-\left(\mu^{a}-\mu^{b}\right)\left(X_{2}+\mu^{b}\right)+\frac{\Omega}{2}\left(\left(\mu^{a}+\frac{p W}{1-p}\right)^{2}-\left(\mu^{b}+\frac{p W}{1-p}\right)^{2}\right] \geq 0\right. \\
\Leftrightarrow \quad L+(1-p)\left[-\left(\mu^{a}-\mu^{b}\right)\left(X_{2}+\mu^{b}\right)+\frac{\Omega}{2}\left(\mu^{a}-\mu^{b}\right)\left(\mu^{a}+\mu^{b}+2 \frac{p W}{1-p}\right)\right] \geq 0 \\
\Leftrightarrow \quad L \geq(1-p)\left(\mu^{a}-\mu^{b}\right)\left(X_{2}+\mu^{b}\right)-(1-p) \frac{\Omega}{2}\left(\mu^{a}-\mu^{b}\right)\left(\mu^{a}+\mu^{b}+2 \frac{p W}{1-p}\right) .
\end{gathered}
$$

An increase in $W$ has no impact when $\Omega=0$ but makes the incentive constraint easier to satisfy when $\Omega>0$. This is because an altruistic incumbent internalizes the positive impact on social welfare (via a more likely reelection of a high ability opponent) of choosing the bad news policy $B$. When $W$ increases, it implies that the opponent can only be elected if she has a high $\mu^{o}$, which reinforces the above incentives to choose policy $B$. Compared with case $\mathrm{S} 2$ ), there is no ambiguity because the increase in $W$ has an impact on the reelection chances of the opponent both when the incumbent chooses $A$ and when she chooses $B$. 
Lemma 8 When $\Omega>0$ ("altruistic" incumbent), the incentive condition for the incumbent to select the congruent policy $B$ when her signal is $b$ is

- S1 always satisfied for strong conformism $\left(W \geq W^{1}(B)=\left[1-\mu^{b}\right](1-p) / p\right)$.

- S2 satisfied if

$$
L \geq(1-p)\left(1-\mu^{b}-\frac{p W}{1-p}\right)\left(X_{2}+\mu^{b}\right)-(1-p) \frac{\Omega}{2}\left[1-\left(\mu^{b}+\frac{p W}{1-p}\right)^{2}\right]
$$

for intermediate conformism $\left(W^{1}(A) \leq W<W^{1}(B)\right)$.

- S3 satisfied if

$$
L \geq(1-p)\left(\mu^{a}-\mu^{b}\right)\left(X_{2}+\mu^{b}\right)-(1-p) \frac{\Omega}{2}\left(\mu^{a}-\mu^{b}\right)\left(\mu^{a}+\mu^{b}+2 \frac{p W}{1-p}\right)
$$

for weak conformism $\left(W<W^{1}(A)=\left[1-\mu^{a}\right](1-p) / p\right)$.

In case S2, the derivative of the right-hand side with respect to $W$ is of the sign of $\frac{p}{1-p}\left[-\left(X_{2}+\mu^{b}\right)+\Omega\left(\mu^{a}-\mu^{b}\right)\left(\mu^{b}+\frac{p W}{1-p}\right)\right]:$ An increase in $W$ always makes the condition easier to satisfy when $\Omega=0$ but not necessarily when $\Omega>0$.

In case S3 to the contrary, an increase in $W$ has no impact on the incentive condition when $\Omega=0$ but makes it easier to satisfy if $\Omega>0$.

Replacing $\Omega$ by zero yields the results in proposition 1, since in that case the incentive condition under signal $a$ is always satisfied.

Lemma 9 When $\Omega>0$ ("altruistic" incumbent) and under the unfavorable signal (b), the impact of an increase in $W$ on separation incentives

- is null for large conformism (S1),

- is ambiguous for intermediate conformism (S2)

- is positive for weak conformism (S3).

\section{A.4. Pooling equilibrium - Proof of propositions 2 and 6}

In a pooling equilibrium, the incumbent chooses policy $A$ whatever her private signal. Beliefs are given by $\mu^{P}(A)=\mu$ (no learning) and out-of-equilibrium beliefs $\mu^{P}(B)=\mu^{b}$ (belief consistent with the intuitive criterion, as discussed in the text). The analysis can be rewritten for any out-of-equilibrium beliefs $\mu^{P}(B)=\mu^{\text {ooe }}>\mu$ by simply replacing $\mu^{b}$ by $\mu^{o o e}$. 
We omit the incentive constraint that ensures that the incumbent prefers to choose $A$ when she has signal $a$. For $\Omega=0$, it is always trivially satisfied (as for the separating equilibrium, and although equilibrium beliefs are not the same). For $\Omega>0$, the same type of complex additional effects arise as in the separating equilibrium. We focus here on the most relevant constraint, the one that ensures that the incumbent prefers to hide a bad-news signal $b$ by choosing policy $A$.

Under the unfavorable signal $b$, choosing the non congruent policy $(A)$ is preferred to the congruent policy $(B)$ if and only if:

$$
\begin{aligned}
X_{1}- & L+p\left(X_{2}+\mu^{b}\right)+(1-p) G\left(\hat{\mu}^{P}\right)\left(X_{2}+\mu^{b}\right)+(1-p)\left(1-G\left(\hat{\mu}^{P}\right)\right) \Omega \frac{1+\hat{\mu}^{P}}{2} \\
\geq & X_{1}+0+p\left(X_{2}+\mu^{b}\right)+(1-p) G\left(\hat{\mu}^{S B}\right)\left(X_{2}+\mu^{b}\right) \\
& +(1-p)\left(1-G\left(\hat{\mu}^{S B}\right)\right) \Omega \frac{1+\hat{\mu}^{S B}}{2}(I C)^{P}(b)
\end{aligned}
$$

This condition simplifies into

$$
\begin{aligned}
& L \leq(1-p) \\
& \qquad \begin{array}{l}
{\left[\left(G\left(\hat{\mu}^{P}\right)-G\left(\hat{\mu}^{S B}\right)\right)\left(X_{2}+\mu^{b}\right)\right.} \\
\left.\quad+\frac{\Omega}{2}\left(\left(1-G\left(\hat{\mu}^{P}\right)\right)\left(1+\hat{\mu}^{P}\right)-\left(1-G\left(\hat{\mu}^{S B}\right)\right)\left(1+\hat{\mu}^{S B}\right)\right)\right] \quad(I C)^{P}(b)
\end{array}
\end{aligned}
$$

- Case P1: $W \geq W^{1}(B)=\left[1-\mu^{b}\right](1-p) / p$. Strong conformism.

We have $G\left(\hat{\mu}^{P}\right)=G\left(\hat{\mu}^{S B}\right)=1$, and the incentive condition simplifies into $-L \geq 0$ which cannot be satisfied.

The condition on $W$ for this case is the same as for case $\mathrm{S} 1\left(W \geq W^{1}(B)\right)$ : The incentive constraint is always satisfied for the $\mathbf{S}$-equilibrium but never for the $\mathbf{P}$-equilibrium.

- Case P2: $[1-\mu](1-p) / p \leq W<\left[1-\mu^{b}\right](1-p) / p$. Intermediate conformism.

We have $G\left(\hat{\mu}^{P}\right)=1$ and $G\left(\hat{\mu}^{S B}\right)=\hat{\mu}^{S B}=\mu^{b}+\frac{p W}{1-p}$. The incentive condition $(I C)^{P}(b)$ then writes as

$$
\begin{aligned}
L \leq & (1-p) \\
& {\left[\left(1-\mu^{b}-\frac{p W}{1-p}\right)\left(X_{2}+\mu^{b}\right)-\frac{\Omega}{2}\left(1-\mu^{b}-\frac{p W}{1-p}\right)\left(1+\mu^{b}+\frac{p W}{1-p}\right)\right] } \\
& \Leftrightarrow \quad L \leq(1-p)\left[\left(1-\mu^{b}-\frac{p W}{1-p}\right)\left(X_{2}+\mu^{b}\right)-\frac{\Omega}{2}\left(1-\left(\mu^{b}+\frac{p W}{1-p}\right)^{2}\right)\right]
\end{aligned}
$$

An increase in $W$ has two effects of opposite direction. The derivative of the righthand side with respect to $W$ is of the sign of $\frac{p}{1-p}\left[-\left(X_{2}+\mu^{b}\right)+\Omega\left(\mu^{b}+\frac{p W}{1-p}\right)\right]$ : An increase in $W$ always makes the condition more difficult to satisfy when $\Omega=0$ but not necessarily when $\Omega>0$. This is because it affects differently the election 
chances of the opponent depending on the decision chosen (under decision $A$, a change in $W$ has no impact on the opponent's prospects since she does not get elected anyway).

- Case P3: $W<[1-\mu](1-p) / p$. Weak conformism.

In that case, $G\left(\hat{\mu}^{P}\right)=\hat{\mu}^{P}=\mu+\frac{p W}{1-p}$ and $G\left(\hat{\mu}^{S B}\right)=\hat{\mu}^{S B}=\mu^{b}+\frac{p W}{1-p}$. The incentive condition $(I C)^{S}(b)$ writes as

$$
\begin{aligned}
-L+(1-p) & {\left[\left(\left(\mu+\frac{p W}{1-p}\right)-\left(\mu^{b}+\frac{p W}{1-p}\right)\right)\left(X_{2}+\mu^{b}\right)\right.} \\
& +\frac{\Omega}{2}\left(\left(1-\mu-\frac{p W}{1-p}\right)\left(1+\mu^{p}+\frac{p W}{1-p}\right)\right. \\
& \left.\left.-\left(1-\mu^{b}-\frac{p W}{1-p}\right)\left(1+\mu^{b}+\frac{p W}{1-p}\right)\right)\right] \geq 0 \\
\Leftrightarrow \quad L \leq(1-p) & \quad\left(\mu-\mu^{b}\right)\left(X_{2}+\mu^{b}\right) \\
& \left.+\frac{\Omega}{2}\left[\left(1-\left(\mu+\frac{p W}{1-p}\right)^{2}\right)-\left(1-\left(\mu^{b}+\frac{p W}{1-p}\right)^{2}\right)\right]\right] \\
\Leftrightarrow \quad & L \leq(1-p)\left[\left(\mu-\mu^{b}\right)\left(X_{2}+\mu^{b}\right)+\frac{\Omega}{2}\left[\left(\mu^{b}+\frac{p W}{1-p}\right)^{2}-\left(\mu+\frac{p W}{1-p}\right)^{2}\right]\right] \\
\Leftrightarrow \quad & L \leq(1-p)\left[\left(\mu-\mu^{b}\right)\left(X_{2}+\mu^{b}\right)+\frac{\Omega}{2}\left(\mu^{b}-\mu\right)\left(\mu+\mu^{b}+2 \frac{p W}{1-p}\right)\right] \\
\Leftrightarrow \quad & L \leq(1-p)\left(\mu-\mu^{b}\right)\left[\left(X_{2}+\mu^{b}\right)-\frac{\Omega}{2}\left(\mu+\mu^{b}+2 \frac{p W}{1-p}\right)\right]
\end{aligned}
$$

An increase in $W$ has no impact when $\Omega=0$ but makes the incentive condition easier to satisfy when $\Omega>0$. This is because an increase in $W$ reduces the chances of the opponent whatever the policy choice of the incumbent in case P3.

\section{A.5. Social welfare}

\section{A.5.1. Social welfare with separation}

Using $\hat{\mu}^{S A}=\mu^{a}+\frac{p}{1-p} W$ and $\hat{\mu}^{S A}=\mu^{a}+\frac{p}{1-p} W$, one can express social welfare for a separating equilibrium as follows: 


$$
\begin{aligned}
& S W(S 1)=\mu\left(1+\mu^{a}\right)+(1-\mu)\left(0+\mu^{b}\right)=\mu\left(1+\mu^{a}\right)+(1-\mu) \mu^{b} \\
& S W(S 2)=\mu\left(1+\mu^{a}\right)+(1-\mu) \\
& {\left[0+\left(p+(1-p) \hat{\mu}^{S B}\right) \mu^{b}+\left(1-p-(1-p) \hat{\mu}^{S B}\right) \frac{1+\hat{\mu}^{S B}}{2}\right]} \\
& =\mu\left(1+\mu^{a}\right)+(1-\mu) \\
& {\left[\left(p+(1-p)\left(\mu^{b}+\frac{p W}{1-p}\right)\right) \mu^{b}\right.} \\
& \left.+(1-p) \frac{1}{2}\left(1-\mu^{b}-\frac{p W}{1-p}\right)\left(1+\mu^{b}+\frac{p W}{1-p}\right)\right] \\
& =\mu\left(1+\mu^{a}\right)+(1-\mu) \\
& {\left[\left(p+(1-p)\left(\mu^{b}+\frac{p W}{1-p}\right)\right) \mu^{b}+(1-p) \frac{1}{2}\left(1-\left(\mu^{b}+\frac{p W}{1-p}\right)^{2}\right)\right]} \\
& S W(S 3)=\mu\left[1+\left(p+(1-p) \hat{\mu}^{S A}\right) \mu^{a}+\left(1-p-(1-p) \hat{\mu}^{S A}\right) \frac{1+\hat{\mu}^{S A}}{2}\right] \\
& +(1-\mu)\left[0+\left(p+(1-p) \hat{\mu}^{S B}\right) \mu^{b}+\left(1-p-(1-p) \hat{\mu}^{S B}\right) \frac{1+\hat{\mu}^{S B}}{2}\right] \\
& =\mu\left[1+\left(p+(1-p) \hat{\mu}^{S A}\right) \mu^{a}+(1-p) \frac{1}{2}\left(1-\hat{\mu}^{S A}\right)\left(1+\hat{\mu}^{S A}\right)\right] \\
& +(1-\mu)\left[\left(p+(1-p) \hat{\mu}^{S B}\right) \mu^{b}+(1-p) \frac{1}{2}\left(1-\hat{\mu}^{S B}\right)\left(1+\hat{\mu}^{S B}\right)\right] \\
& =\mu\left[1+\left(p+(1-p) \hat{\mu}^{S A}\right) \mu^{a}+(1-p) \frac{1}{2}\left(1-\left(\mu^{a}+\frac{p W}{1-p}\right)^{2}\right)\right] \\
& +(1-\mu)\left[\left(p+(1-p) \hat{\mu}^{S B}\right) \mu^{b}+(1-p) \frac{1}{2}\left(1-\left(\mu^{b}+\frac{p W}{1-p}\right)^{2}\right)\right]
\end{aligned}
$$

For weak conformism, social welfare in the separating equilibrium is decreasing in $W$.

For intermediate conformism, two effects of opposite directions arise. Social welfare varies with $W$ as the following expression: $\mu^{b} \frac{p W}{1-p}-\frac{1}{2}\left(\mu^{b}+\frac{p W}{1-p}\right)^{2}$. The derivative is of the sign of $\frac{p}{1-p} \mu^{b}-\frac{p}{1-p}\left(\mu^{b}+\frac{p}{1-p} W\right)=-\left(\frac{p}{1-p}\right)^{2} W$. So welfare is also decreasing in $W$ for intermediate conformism.

This analysis within the different cases is however not a global analysis of the impact of conformism: An increase in $W$ can indeed induce a change in the expression of social welfare (from case S3) to S2, or to S1. The analysis of the impact of conformism on social welfare is therefore complex and this impact is non monotonous.

\section{A.5.2. Social welfare with pooling}

Similarly, social welfare in the pooling equilibrium is: 


$$
\begin{aligned}
S W(P 2)= & \mu\left(1+\mu^{a}\right)+(1-\mu)\left(-L+\mu^{b}\right) \\
S W(P 3)= & \mu\left[1+(p+(1-p) \hat{\mu}) \mu^{a}\right]+(1-\mu)\left[-L+(p+(1-p) \hat{\mu}) \mu^{b}\right] \\
& +(1-p-(1-p) \hat{\mu}) \frac{1+\hat{\mu}}{2} \\
= & \mu\left[1+(p+(1-p) \hat{\mu}) \mu^{a}\right]+(1-\mu)\left[-L+(p+(1-p) \hat{\mu}) \mu^{b}\right] \\
& +(1-p) \frac{1}{2}(1-\hat{\mu})(1+\hat{\mu}) \\
= & \mu\left[1+(p+(1-p) \hat{\mu}) \mu^{a}\right]+(1-\mu)\left[-L+(p+(1-p) \hat{\mu}) \mu^{b}\right] \\
& +(1-p) \frac{1}{2}\left(1-\hat{\mu}^{2}\right) \\
= & \mu\left[1+(p+(1-p) \hat{\mu}) \mu^{a}\right]+(1-\mu)\left[-L+(p+(1-p) \hat{\mu}) \mu^{b}\right] \\
& +(1-p) \frac{1}{2}\left(1-\left(\mu+\frac{p W}{1-p}\right)^{2}\right)
\end{aligned}
$$

Recall that for strong conformism (P1), no pooling equilibrium exists. And the reelection probability of the incumbent is independent from the true signal, as she always chooses $A$ and is always perceived as being of the prior ability $\mu$.

For weak conformism, social welfare in the pooling equilibrium is decreasing in $W$.

\section{A.5.3. A discussion of possible impacts of increases in $W$}

Under separation, assume that $W$ increases marginally from under to above $W^{1}(B)$ : this leads to moving from S3 to $\mathrm{S} 2$. Similarly, if $W$ increases marginally from under to above $W^{1}(A)$, one moves from equilibrium configuration $\mathrm{S} 2$ to $\mathrm{S} 1$. In both cases, the efficiency of decisions is unchanged (they are always congruent under separation). But the incumbent is more often re-elected, although she is less appropriate than the opponent $\left(\mu<\mu^{o}\right)$. The effects on social welfare are respectively $S W(S 1)-S W(S 2)<0^{32}$ and $S W(S 2)-S W(S 3)<0$. This measures the candidate selection cost of an increase in conformism, when the equilibrium was separating anyway.

Under pooling, consider a marginal increase in $W$ from under to above $W^{1 P}$ (the minimum conformism level ensuring reelection with probability 1 under pooling). This leads to moving from P3 to P2. It has an ambiguous effect: both types of incumbent ('appropriate' to future circumstances or not) are re-elected more often. The effect on social welfare is $S W(P 2)-S W(P 3)=[1-(p+(1-p) \hat{\mu})]$ $\left[\mu \mu^{a}-(1-\mu) \frac{1}{2}\left(\left(\mu-\mu^{b}\right)+\left(1+\frac{p}{1-p} W-\mu^{b}\right)\right)\right]$ whose sign is not determined, due to the two opposing effects in the second bracketed term.

A marginal increase in $W$ from under to above $W^{1}(B)$, that moves the equilibrium from $\mathrm{P} 2$ to $\mathrm{S} 1$ would create a welfare gain of $S W(S 1)-S W(P 2)=(1-\mu) L>0$. In $\mathrm{P} 2$ as in $\mathrm{S} 1$, the incumbent is always reelected, so that no effect arises from candidate

$\overline{32 S W(S 1)-S W(S 2)=(1-\mu)(1}-\left(p+(1-p)\left(\mu^{b}+\frac{p}{1-p} W\right)\right) \frac{1}{2}\left(1-\mu^{b}-\frac{p}{1-p} W\right)<0$. 
selection. But a positive effect arises from the incumbent's selection of a congruent decision.

Moving from P3 to S2 would both avoid some losses from pandering and improve candidate selection, as voters would have a better information on the incumbent's appropriateness.

Acknowledgements Aubert gratefully acknowledges funding from ANR under Grant ANR-17EURE-0010 (Investissements d'Avenir program) and from IdEx université de Bordeaux/GPR HOPE (Investissements d'Avenir program) as well as a delegation contract with INRAe at GAEL.

\section{References}

Agranov M, Goeree JK, Romero J, Yariv L (2017) What makes voters turn out: the effects of polls and beliefs. J Eur Econ Assoc 16(3):825-856

Ansolabehere S (2002) The incumbency advantage in US elections: an analysis of state and federal offices, 1942-2000. Elect Law J 1(3):315-338

Ansolabehere S, Snyder JM Jr, Snowberg EC, Snyder Jr JM (2006) Television and the incumbency advantage in US elections. Legis Stud Q 31(4):469-490

Ansolabehere S, Snyder JM Jr, Hansen JM, Hirano S, Snyder Jr JM (2007) The incumbency advantage in US primary elections. Elect Stud 26(3):660-668

Asch SE (1951) Effects of group pressure upon the modification and distortion of judgments. In: Guetzkow H (ed) Groups, leadership, and men. Carnegie Press, Pittsburgh

Ashworth S, Mesquita EBD (2008) Electoral selection, strategic challenger entry, and the incumbency advantage. J Polit 70(4):1006-1025

Ashworth S, De Mesquita EB, Shotts KW (2010) Does informative media commentary reduce politicians' incentives to pander? J Public Econ 94(11):838-847

Ashworth S, De Mesquita EB, Shotts KW (2010) Does informative media commentary reduce politicians' incentives to pander? J Public Econ 94(11-12):838-847

Bartels LM (2000) Partisanship and voting behavior, 1952-1996. Am J Polit Sci 44(1):35-50

Bartels LM (2002) Beyond the running tally: Partisan bias in political perceptions. Polit Behav 24(2):117-150

Bischoff I, Egbert H (2013) Social information and bandwagon behavior in voting: an economic experiment. J Econ Psychol 34:270-284

Brader TA, Tucker JA (2009) What's left behind when the party's over: survey experiments on the effects of partisan cues in Putin's Russia. Polit Policy 37(4):843-868

Callander S (2007) Bandwagons and momentum in sequential voting. Rev Econ Stud 74(3):653-684

Callander S (2008) Majority rule when voters like to win. Games Econom Behav 64(2):393-420

Canes-Wrone B, Herron MC, Shotts KW (2001) Leadership and pandering: a theory of executive policymaking. Am J Polit Sci 45(3):532-550

Cho I-K, Kreps DM (1987) Signaling games and stable equilibria*. Q J Econ 102(2):179-221

Cialdini RB, Goldstein NJ (2004) Social influence: compliance and conformity. Ann Rev Psychol 55:591-621

Claidière N, Whiten A (2012) Integrating the study of conformity and culture in humans and nonhuman animals. Psychol Bull 138(1):126-145

Deutsch M, Gerard HB (1955) A study of normative and informational social influences upon individual judgment. Psychol Sci Public Interest 51(3):629-636

Ding H (2017) Conformity preferences and information gathering effort in collective decision making. BE J Theor Econ 18(1):1-18

Dur RAJ (2001) Why do policy makers stick to inefficient decisions? Public Choice 107(3):221-234

Erikson RS (1971) The advantage of incumbency in congressional elections. Polity 3(3):395-405

Erikson R, Titiunik R (2015) Using regression discontinuity to uncover the personal incumbency advantage. Quart J Polit Sci 10(1):101-119

Falk A, Zimmermann F (2017) Consistency as a signal of skills. Manage Sci 63(7):2197-2210 
Feddersen TJ, Pesendorfer W (1996) The swing voter's curse. Am Econ Rev 86:408-424

Feddersen T, Pesendorfer W (1997) Voting behavior and information aggregation in elections with private information. Econometrica 65:1029-1058

Fiva JH, Røhr HL (2018) Climbing the ranks: incumbency effects in party-list systems. Eur Econ Rev 101:142-156

Gelman A, King G (1990) Estimating incumbency advantage without bias. Am J Polit Sci 34(4):1142-1164

Gerber A (1998) Estimating the effect of campaign spending on senate election outcomes using instrumental variables. Am Polit Sci Rev 92(02):401-411

Gerber AS, Huber GA (2009) Partisanship and economic behavior: do partisan differences in economic forecasts predict real economic behavior? Cambridge Univ Press, Cambridge

Grodner A, Kniesner TJ (2006) Social interactions in labor supply. J Eur Econ Assoc 4(6):1226-1248

Helland L, Sørensen RJ (2015) Partisan bias, electoral volatility, and government efficiency. Elect Stud 39:117-128

Hodgson R, Maloney J (2013) Bandwagon effects in British elections, 1885-1910. Public Choice 157(1):73-90

Hodler R, Loertscher S, Rohner D (2010) Inefficient policies and incumbency advantage. J Public Econ 94(9-10):761-767

Kiss Á, Simonovits G (2014) Identifying the bandwagon effect in two-round elections. Public Choice 160(3):327-344

Klar S (2014) Partisanship in a social setting. Am J Polit Sci 58(3):687-704

Lee DS (2008) Randomized experiments from non-random selection in US House elections. J Econ 142(2):675-697

Lee W (2011) Bandwagon, underdog, and political competition: the uni-dimensional case. Soc Choice Welfare 36(3):423-449

Levitt SD, Wolfram CD (1997) Decomposing the sources of incumbency advantage in the US House. Legislat Stud Quart 22(1):45-60

Majumdar S, Mukand SW (2004) Policy gambles. Am Econ Rev 94(4):1207-1222

Maskin E, Tirole J (2004) The politician and the judge: accountability in government. Am Econ Rev 94(4):1034-1054

Morton RB, Muller D, Page L, Torgler B (2015) Exit polls, turnout, and bandwagon voting: evidence from a natural experiment. Eur Econ Rev 77:65-81

Panova E (2015) A passion for voting. Games Econom Behav 90:44-65

Pivato M (2017) Epistemic democracy with correlated voters. J Math Econ 72(7):51-69

Prior M (2006) The incumbent in the living room: the rise of television and the incumbency advantage in US House elections. J Polit 68(3):657-673

Snyder JM, Folke O, Hirano S (2015) Partisan imbalance in regression discontinuity studies based on electoral thresholds. Polit Sci Res Methods 3(02):169-186

Spence M (1973) Job market signaling. Q J Econ 87(3):355-374

Swank OH (1995) Rational voters in a partisanship model. Soc Choice Welfare 12(1):13-27

Tajika T (2021) Persistent and snap decision-making. J Econ Manag Strategy 30(1):203-227

Trounstine J (2011) Evidence of a local incumbency advantage. Legis Stud Q 36(2):255-280

Zafar B (2011) An experimental investigation of why individuals conform. Eur Econ Rev 55(6):774-798

Publisher's Note Springer Nature remains neutral with regard to jurisdictional claims in published maps and institutional affiliations. 